This document is published in:

International Economic Review (2003), 44(3), 827-862.

DOI: 10.1111/1468-2354.t01-1-00091

(c) 2003 John Wiley \& Sons. 


\title{
MORE ON MARRIAGE, FERTILITY, AND THE DISTRIBUTION OF INCOME
}

\author{
By Jeremy Greenwood, NeZIH Guner, AND John A. KNOWLES ${ }^{1}$ \\ University of Rochester; Pennsylvania State University; \\ University of Pennsylvania
}

\begin{abstract}
According to Pareto (1896), the distribution of income depends on "the nature of the people comprising a society, on the organization of the latter, and, also, in part, on chance." In the model developed here the "nature of the people" is captured by attitudes toward marriage, divorce, fertility, and children. Singles search for mates in a marriage market. Married agents bargain about work, and the quantity and quality of children. They can divorce. Social policies, such as child support requirements, reflect the "organization of the (society)." Finally, "chance" is modeled by randomness in income, marriage opportunities, and marital bliss.
\end{abstract}

\section{INTRODUCTION}

At any point of time in the United States some adults are married while others are not, some women have large families and others have small ones, some families are rich, while others are poor, and some children can expect a bright future, others a dim one. Why do families differ so much and does it matter? This is the question addressed here. To answer it, an overlapping generations model of the family is built. The model has four key ingredients. First, marriage is modeled along the search-theoretic lines of Mortensen (1988). Each period males and females must make a decision on whether or not to stay with their mates. If an adult rejects his or her mate, then he or she is free to look for another one in the future. Second, in line with the work by Mansur and Brown (1980) and McElroy and Horney (1981), decisions within a marriage are arrived at via Nash bargaining. Third, as in Becker and Barro (1988) and Razin and Ben-Zion (1975), adults decide on how many children to have. Fourth, following the work of Becker and Tomes (1986) and Loury (1981), parents must decide how much time and goods to invest in their children. In addition to luck, these parental investments determine the productivity of a child when he or she grows up.

In the equilibrium modeled heterogeneity abounds. Some people are married, others are either divorced or single. There are large families and there are small

\footnotetext{
${ }^{1}$ The authors thank John Kennan for advice that shaped the inception of this research. Richard Rogerson, the Editor, and two referees also provided useful comments. Excellent research assistance was performed by Marina Adshade. Financial support from the NSF and SSHRC is gratefully acknowledged. Please address correspondence to: J. Greenwood, Department of Economics, University of Rochester, Harkness Hall, P.O. Box 270156, Rochester, NY 14627-0156, USA. Phone: 585-275-5252. Fax: 585-256-2309. E-mail: gree@troi.cc.rochester.edu.
} 
ones. Households run the gamut from rich to poor. Some children can expect to lead fortunate lives, while others cannot. As in the real world, family structure matters. In the model a significant number of children live with a single mother. Some of these mothers never wed, others are divorced. These children grow up to earn much less than children raised in a two-parent family. The girls from single-parent families are also more likely to experience an out-of-wedlock birth or a divorce than the girls from two-parent families. And so the cycle perpetuates itself, implying a low degree of intergenerational mobility. There is also a negative relationship between income and fertility. That is, poor families tend to have more children. This exacerbates income inequality. To illustrate the model's mechanics two policy experiments are undertaken. Specifically, the effects of child tax credits and child support payments are investigated.

This is not the only dynamic general equilibrium model of marriage and divorce. ${ }^{2}$ Aiyagari et al. (2000) have combined the Mortensen (1988) paradigm with the Becker and Tomes (1986) framework to model the plight of single-parent families. In their analysis family size is held fixed. Husband and wife play a noncooperative Nash game. Regalia and Ríos-Rull (2001) also develop a model of marriage and divorce to analyze the rise in single motherhood since the 1970s. They attribute a significant fraction of this increase to the (relative) rise in female wages. In their setup a single decision maker maximizes some common set of preferences for the family - the unitary preference model. Two questions arise. Why explore the utility of Nash bargaining as a solution concept for family decision making? And, is it important to factor fertility into general equilibrium analyses of the family? As will be seen, both of these ingredients have important implications for any analysis of family-oriented public policies. Therefore, if society wants effective antipoverty programs, they should be investigated. The case for including these features in dynamic general equilibrium models of marriage and divorce is now presented.

Nash bargaining: So, why use Nash bargaining to model decisions within the household? First, males and females may have differences in attitudes toward the desirable quantity and quality of children. In fact, this is inevitable if divorce is permitted. While it may be reasonable to assume that a male and female share the same momentary utility in marriage, it is not reasonable to assume that they do upon divorce. For in life after divorce each party's income and expenditure will differ, they may remarry, etc. Forward-looking agents will take the possibility of divorce into account before and during marriage. This will lead to differences in attitudes toward kids, even if they share the same momentary utility in marriage. For instance, imagine that a couple would both like five children and believe that the woman should stay at home and raise them, at least provided that the marriage lasts. The woman realizes that if a divorce occurs she will be

\footnotetext{
2 The need for dynamic general equilibrium models of the family has been noted by labor economists. For instance, Weiss (1997, pp. 120) in his excellent survey on the literature on marriage and divorce states that when "examining the economic contributions, the main obstacle is the scarcity of equilibrium models which carefully tie the individual behavior with the market constraints and outcomes. Consequently, we do not yet have a convincing model which explains aggregate family formation and dissolution."
} 
stuck raising five children and have no work experience. Consequently, when taking the possibility of divorce into account, she may prefer to have fewer children and go to work. Nash bargaining allows for such differences in tastes to be easily reconciled. One party can effect transfers to the other until an agreement is attained. ${ }^{3}$

Second, there is evidence that allocations within the household are not decided in a manner consistent with a single decision maker who maximizes some common set of preferences for the family - the unitary decision model. For instance, when government child allowances were transferred from husbands to wives in the United Kingdom during the late 1970s intrahousehold resource allocations tilted toward wives; see Lundberg et al. (1997). Furthermore, the higher the ratio of eligible males to females in a population, the more resource allocations within a marriage favor the wife. According to Chiappori et al. (2002) this finding is consistent with a Nash bargaining model where each party takes into account the value of their options outside of the marriage, that is, the value of being single while factoring in the probability of finding a future mate. This is exactly the type of framework that is modeled here. In a similar vein, Rubalcava and Thomas (2000) find that the presence of AFDC shifts resources allocations in low-income married households with children toward women, presumably because it raises the outside option of single life for women. ${ }^{4}$

Third, the assumed mode of household decision making matters. It has important implications for the public policy predictions that arise from models of marriage, divorce, and fertility. For example, take the case of child support payments studied here. These payment are designed to help the plight of children living with divorced mothers. Males will find marriage less attractive when they have to make child support payments upon divorce. Suppose they do have to make these payments. In the parameterized version of the model presented, the equilibrium number of marriages plummets when a unitary decision model is assumed. There is only a moderate decline in the number of marriages, however, when Nash bargaining is assumed. This occurs because young females make offsetting transfers to young males to make marriages viable. Hence, intrahousehold reallocations may have important implications for society's redistribution programs. This needs to be studied.

Fertility: Why is it important to include a fertility decision in models of marriage and divorce? First, to most, the decisions to get married and have children are inextricably linked. Therefore, it seems natural to model these two choices together. Furthermore, family structure and the well-being of children are closely connected empirically. Other things equal, families with lower incomes tend to have more children (see Knowles, 1999). Additionally, single mothers tend to have more children than married ones. Hence, resources per child are less in low-income families

\footnotetext{
${ }^{3}$ In a unitary decision model of marriage these differences in attitudes are difficult to resolve. Regalia and Ríos-Rull (2001) resolve this conflict by letting the woman in a match choose the number of children to have. Women make this choice knowing that other household decisions will be taken to maximize a joint utility function.

${ }^{4}$ In fact, Greenwood et al. (2000) use the model developed here to study AFDC. They find this, precisely.
} 
(often single-parent families), both because there is less income and because this income has to be spread over more members. This has implications for income inequality at a point in time and for the transmission of inequality across time. For example, it is well known that children from single-parent families are much more likely to drop out of school, to be unemployed, and to experience out-of-wedlock births (McLanahan and Sandefur, 1994). It is an interesting question to ask why a woman should choose to have children out of wedlock. The answer to this can only come from a model where both the decisions to marry and have children are modeled explicitly.

Second, the reason for most antipoverty programs is to improve the welfare of children. To design effective public policy programs, the impact that antipoverty schemes have on fertility must be taken into account. Take for example the child tax credit program studied here. With child tax credits, on average families with children will now have more income per child, other things being equal. Thus, their children should be better off. But, other things may not be equal, if such a policy promotes larger family size. In the calculations undertaken here, a child tax credit fails to elevate the level of well-being in society precisely due to an increase in family size.

\section{ECONOMIC ENVIRONMENT}

Consider an economy populated by two groups of agents, females and males. Agents live for four periods: two periods as children, and two periods as adults. Let young and old refer to the first and second periods of adulthood, respectively. At any point in time, the female and male populations each consist of a continuum of children and a continuum of adults. Children become adults after they have been raised by their parents for two periods. Each adult is indexed by a productivity level. Let $x$ denote the type (productivity) of an adult female, and $z$ denote the type (productivity) of an adult male. Assume that $x$ and $z$ are contained in the sets $\mathcal{X}=\left\{x_{1}, x_{2}, \ldots, x_{S}\right\}$ and $\mathcal{Z}=\left\{z_{1}, z_{2}, \ldots, z_{S}\right\}$.

At the beginning of each period, there exists a marriage market for single agents. Any single agent can take a draw from this market. Agents are free to accept or reject a mate as they desire. If a single agent accepts a draw, she/he is married for the current period, provided of course, that the other person agrees too. Otherwise, the agent is single and can take a new draw at the beginning of the next period. Similarly, at the beginning of each period, married agents decide to remain married or get divorced. A divorced agent needs to remain single one period before having a new draw. Therefore, given the two-period overlapping generations structure remarriage is ruled out. Furthermore, assume that agents only match with people of the same generation.

Females are only fecund for the first period of their adult life. Therefore, each period, young married couples and young single adult females decide how many children to have. A child has equal chances of being a female or a male. Let $k$ denote the number of children a female has. Assume that $k$ is contained in the set $\mathcal{K}=\{0,1, \ldots, K\}$. Children stay with their mothers, if their parents get divorced. A divorced male has to pay child support payments to his former wife after divorce. 
Agents are endowed with one unit of (nonsleeping) time in each period. Females must split this time between work, child care, and leisure. Males divide their time between work and leisure. Mothers and married fathers have to spend a fixed amount of time per child on homework.

Married agents derive utility from the consumption of a public household good, from human capital investment in their children, from leisure, and from marital bliss. Consumption of this household good depends upon the number of adults and children in the family. Parents must decide how much time and goods to invest in their children. This determines the level of human capital possessed by their children. Parents treat their children equally. Single males care only about their own consumption of goods and leisure and they do not worry about human capital investment in their children. When a male marries a female with children, however, he derives utility from the human capital investment in his stepchildren. A single mother must make the decision on her own about how much time and money to invest in her kids.

After two periods with their mother, children are endowed with productivity levels that depend on the human capital investment received throughout their childhood. Each period the oldest adult males and females die and are replaced by the oldest children who enter into the marriage market.

\subsection{Preferences}

Females: Let the momentary utility function for a woman be

$$
\begin{aligned}
F(c, e, k, 1-l-t) & \equiv U(c)+V(e, k)+R\left(1-l-t-\iota_{f} k\right) \\
& \equiv \frac{c^{v_{f}}}{v_{f}}+\frac{k^{\xi_{f}}}{\xi_{f}} \frac{e^{\vartheta_{f}}}{\vartheta_{f}}+\delta_{f} \frac{\left(1-l-t-\iota_{f} k\right)^{\varsigma_{f}}}{\varsigma_{f}}
\end{aligned}
$$

Here $c$ is the consumption of household production, which is a public good for the family, $k$ is the number of children, and $e$ is human capital investment per child. Females allocate $l$ units of their time for work, and $t$ units of it for child care or nurture. They also incur a fixed time cost of $\iota_{f}$ per child.

Males: A male's attitude toward children depends upon his marital status. Males spend $n$ units of their time working. The utility function for a married male is described by

$$
\begin{aligned}
M(c, e, k, 1-n) & \equiv U(c)+P(e, k)+S\left(1-n-\iota_{m} k\right) \\
& \equiv \frac{c^{v_{m}}}{v_{m}}+\frac{k^{\xi_{m}}}{\xi_{m}} \frac{e^{\vartheta_{m}}}{\vartheta_{m}}+\delta_{m} \frac{\left(1-n-\iota_{m} k\right)^{\zeta_{m}}}{\varsigma_{m}}
\end{aligned}
$$

Married males incur a fixed time cost of $\iota_{m}$ per child. The functions $V$ and $P$ imply that the married male's attitudes toward the welfare of children is allowed to differ from that of the female. The utility function for a single male can be expressed simply as $M(c, 0,0,1-n)$; a single male does not realize any utility from his children born through a previous relationship. 
2.2. Household Consumption. Let $p$ denote the number of parents in a household. Then, the consumption for a household with $p$ parents and $k$ children is given by

$$
c=\Psi(p, k)[Y(l, n ; x, z)-d]-\gamma J(q), \quad \text { for } \quad q=m, s
$$

where

$$
\Psi(p, k)=\left(\frac{1}{p+b k}\right)^{\eta}, \quad 0<\eta<1, \quad 0<b<1
$$

and

$$
Y(l, n ; x, z)= \begin{cases}(x l+z n), & \text { for a married couple } \\ x l, & \text { for a single woman } \\ z n, & \text { for a single man }\end{cases}
$$

and where the indicator function $J$ returns a value of one for a married household and zero otherwise so that $J(m)=1$ and $J(s)=0$.

The function $Y$ has a clear interpretation under the above parameterization. The variables $x$ and $z$ can be thought of as the market wages for type- $x$ females and type- $z$ males. The function $\Psi$ translates household production into the consumption realized by adult family members. There are scale effects in household consumption in the sense that each additional child costs less to feed and clothe than the one before. Still, it does cost more to maintain the extra child. Likewise, the second adult costs less than the first. The variable $d$ represents the amount of household production that is used for investment in children. A single male will always set this to zero, because, either he has no children or he does not realize utility from them.

The parameter $\gamma$ represents the quality of the match between a male and a female. Let $\gamma \in \mathcal{G}=\left\{\gamma_{1}, \gamma_{2}, \ldots, \gamma_{m}\right\}$ be a discrete random variable. For an unmarried couple this variable is drawn, after they are matched but before the marriage decision, according to distribution function $\Gamma\left(\gamma_{h}\right)=\operatorname{Pr}\left[\gamma=\gamma_{h}\right]$. For a married couple the variable $\gamma$ then evolves over time according the process $\Delta\left(\gamma_{n} \mid \gamma_{h}\right)=$ $\operatorname{Pr}\left[\gamma^{\prime}=\gamma_{n} \mid \gamma=\gamma_{h}\right]$. Given the value drawn for $\gamma^{\prime}$, each party in a marriage decides whether to remain married.

2.3. Transmission of Human Capital. Human capital investment per child in a household with $k$ children is given by

$$
e=Q(t, d, k) \equiv\left(\frac{t}{k^{\kappa_{1}}}\right)^{\alpha}\left(\frac{d}{k^{\kappa_{2}}}\right)^{1-\alpha}, \quad \text { for } \quad 0<\kappa_{1}, \kappa_{2}<1
$$

which transforms the child-care time of the mother, $t$, and inputs of goods, $d$, into human capital investment, $e$. Recall that children are nurtured for two periods. At the end of every period the children of the oldest generation enter into the 
marriage market as single adults. The productivity levels for females are drawn from the distribution

$$
\Xi\left(x_{i} \mid e_{-2}+e_{-1}\right)=\operatorname{Pr}\left[x=x_{i} \mid e_{-2}+e_{-1}\right]
$$

and for males from

$$
\Lambda\left(z_{j} \mid e_{-2}+e_{-1}\right)=\operatorname{Pr}\left[z=z_{j} \mid e_{-2}+e_{-1}\right]
$$

where $e_{-1}$ and $e_{-2}$ indicate the human capital investment during the two periods of an agent's childhood. The distribution functions $\Xi$ and $\Lambda$ are stochastically increasing in $e_{-2}+e_{-1}$ in the sense of first-order stochastic dominance. Thus, higher human capital investment in children by parents increases the likelihood that children will be successful in life.

The conditional distribution $\Xi$ is represented by a discrete approximation to a lognormal distribution with mean, $\mu_{x \mid e}$, and standard deviation, $\sigma_{x \mid e}$. Similarly, suppose that $\Lambda$ is also given by a discrete approximation to a lognormal with mean, $\mu_{z \mid e}$, and standard deviation, $\sigma_{z \mid e}$. These conditional means are given by

$$
\mu_{x \mid e}=\ln \left[\varepsilon_{1}\left(e_{-2}+e_{-1}\right)^{\varepsilon_{2}}\right], \quad \text { for } \quad \varepsilon_{2} \in(0,1)
$$

and

$$
\mu_{z \mid e}=\ln \left[\varepsilon_{1}\left(e_{-2}+e_{-1}\right)^{\varepsilon_{2}}+\mu\right]
$$

where the $\varepsilon$ 's are the parameters governing the technology that maps human capital investment by parents into productivity levels.

After the first period of adulthood the productivity levels for females and males evolve according to the following transition functions:

$$
X\left(x_{j} \mid x_{i}\right)=\operatorname{Pr}\left[x^{\prime}=x_{j} \mid x=x_{i}\right]
$$

and

$$
Z\left(z_{j} \mid z_{i}\right)=\operatorname{Pr}\left[z^{\prime}=z_{j} \mid z=z_{i}\right]
$$

where $x^{\prime}$ and $z^{\prime}$ denote the next-period values. These Markov chains are constructed to approximate an $\mathrm{AR}(1)$ in logarithms. ${ }^{5}$ The means and standard deviations for these approximations are given by $\mu_{x}\left(1-\rho_{x}\right)+\rho_{x} \ln (x)$ and $\sigma \sqrt{1-\rho_{x}^{2}}$ for females, and by $\mu_{z}\left(1-\rho_{z}\right)+\rho_{z} \ln (z)$ and $\sigma \sqrt{1-\rho_{z}^{2}}$ for males.

\footnotetext{
${ }^{5}$ The discrete approximations for $\Xi, \Lambda, X$, and $Z$ follow the procedure outlined in Tauchen (1986).
} 


\section{DECISION MAKING}

3.1. Household Activity-Single Old Adults. A single old female of type $x$ with $k$ children will solve the following problem:

$$
G_{2}(x, k, z)=\max _{l, t, d} F(c, e, k, 1-l-t)
$$

subject to

$$
c=\Psi(1, k)[Y(l, 0 ; x, 0)+A(z, k)-d]
$$

and

$$
e=Q(t, d, k)
$$

where

$$
A(z, k)=a z N^{s}(z, k) k \text { with } 0 \leq a<1
$$

Here $z$ denotes her former husband's productivity and the function $N^{s}(z, k)$ denotes his labor supply. The function $A$ determines how much child support a former husband has to pay, which is assumed to be a fraction, $a$, of his current income, $z N^{s}(z, k)$, per child. For a single old female who was never married set $z=0$.

Denote a single mother's level of human capital investment in her children by

$$
e=E_{2}^{s}(x, k, z)
$$

This implies that $E_{2}^{s}(x, k, z)=Q\left(T_{2}^{s}(x, k, z), D_{2}^{s}(x, k, z), k\right)$, where $T_{2}^{s}(x, k, z)$ and $D_{2}^{s}(x, k, z)$ are the decision rules for $t$ and $d$ that arise from $\mathrm{P}(1)$.

The maximized utility of a single old male is given by the following problem:

$$
B_{2}(z, k)=\max _{n} M(c, 0,0,1-n)
$$

subject to

$$
\begin{aligned}
c & =\Psi(1,0)[Y(0, n ; 0, z)-a z n k] \\
& =z n-a z n k=z n(1-a k)
\end{aligned}
$$

where $k$ denotes the number of children for whom he has to pay child support. For a single old male who was never married $k=0$.

\subsection{Household Activity-Old Married Adults with $k$ Children}

Nash bargaining problem: Consider a couple of type $(x, z, \gamma, k)$ that is married in the second period. Assume that they make their decisions by applying the Nash solution to a fixed-threat bargaining game. Their problem is to solve 
$\mathrm{P}(3) \max _{l, t, n, d}\left[F(c, e, k, 1-l-t)-G_{2}(x, k, z)\right] \times\left[M(c, e, k, 1-n)-B_{2}(z, k)\right]$

subject to

$$
c=\Psi(2, k)[Y(l, n ; x, z)-d]-\gamma=\Psi(2, k)[x l+z n-d]-\gamma
$$

and

$$
e=Q(t, d, k)
$$

Here $B_{2}(z, k)$ and $G_{2}(x, k, z)$ are the threat points for the husband and wife. They are the values of being single in the second period, and are given by the solutions to the old single agent problems, $\mathrm{P}(1)$ and $\mathrm{P}(2)$.

Denote the level of human capital investment per child in a family with two old parents by

$$
e=E_{2}^{m}(x, z, \gamma, k)
$$

Let the resulting utility levels for an old husband and wife in a type- $(x, z, \gamma, k)$ marriage, or the values for $M$ and $F$ in $\mathrm{P}(3)$ evaluated at the optimal choices for $l, t, n, d$ and the implied values for $c$ and $e$, be represented by

$$
H_{2}(x, z, \gamma, k)
$$

and

$\mathrm{P}^{\prime}(3) \quad W_{2}(x, z, \gamma, k)$

3.3. Marriage-Old Adults. Consider an age-2 couple indexed by $(x, z, \gamma, k)$. Each party faces a decision: Should she/he choose married or single life for the period. Clearly, a married female will want to remain married if and only if $W_{2}(x, z, \gamma, k) \geq G_{2}(x, k, z)$; otherwise, it is in her best interest to get a divorce. Equally as clearly, a single female will desire to marry if and only if $W_{2}(x, z, \gamma, k) \geq G_{2}(x, k, 0)$; otherwise, she will go it alone. Similarly, a married male would wish to remain so if and only if $H_{2}(x, z, \gamma, k) \geq B_{2}(z, k)$, while a single male will like to marry if and only if $H_{2}(x, z, \gamma, k) \geq B_{2}(z, 0)$.

The matching decision of an age- 2 couple can summarized by the following indicator function:

$\mathrm{P}(4)$

$$
\begin{aligned}
& I_{2}^{q}(x, z, \gamma, k) \\
& \quad= \begin{cases}1, & \text { if } W_{2}(x, z, \gamma, k) \geq G_{2}(x, k, J(q) z) \text { and } H_{2}(x, z, \gamma, k) \geq B_{2}(z, J(q) k) \\
0, & \text { otherwise }\end{cases}
\end{aligned}
$$

which is defined for $q=m$, s, where $J(m)=1$ and $J(s)=0$. Note the indicator function depends upon the marital status, $q$, at the beginning of period two. 
3.4. Household Activity-Single Young Adults. Now, let the odds of drawing a single age- 1 female of type $x_{i}$ in the marriage market be represented by

$$
\Phi_{1}\left(x_{i}\right), \quad \text { where } \Phi_{1}\left(x_{i}\right) \geq 0 \forall x_{i} \text { and } \sum_{i=1}^{S} \Phi_{1}\left(x_{i}\right)=1
$$

and the odds of meeting a single age-2 female of type $x_{i}$ with $k$ children in the marriage market be given by

$$
\Phi_{2}\left(x_{i}, k\right), \quad \text { where } \Phi_{2}\left(x_{i}, k\right) \geq 0 \forall x_{i} \quad \text { and } \quad \sum_{i=1}^{S} \sum_{k=0}^{K} \Phi_{2}\left(x_{i}, k\right)=1
$$

Likewise, the odds of meeting a single age- $j$ male of type $z_{i}$ will be denoted by

$$
\Omega_{j}\left(z_{i}\right), \quad \text { where } \Omega_{j}\left(z_{i}\right) \geq 0 \forall z_{i} \text { and } \sum_{i=1}^{S} \Omega_{j}\left(z_{i}\right)=1
$$

A key step in the analysis will be to compute these matching probabilities.

The programming problem for a one-period-old single type- $x_{i}$ female is $\mathrm{P}(5)$

$$
\begin{aligned}
& G_{1}\left(x_{i}\right)=\max _{k, l, t, d}\{F(c, e, k, 1-l-t) \\
&+\beta \sum_{k=1}^{S} \sum_{l=1}^{S} \sum_{n=1}^{m}\left\{W_{2}\left(x_{k}, z_{l}, \gamma_{n}, k\right) I_{2}^{s}\left(x_{k}, z_{l}, \gamma_{n}, k\right)\right. \\
&\left.\quad+G_{2}\left(x_{k}, k, 0\right)\left[1-I_{2}^{s}\left(x_{k}, z_{l}, \gamma_{n}, k\right)\right]\right\} \\
&\left.\times X\left(x_{k} \mid x_{i}\right) \Omega_{2}\left(z_{l}\right) \Gamma\left(\gamma_{n}\right)\right\}
\end{aligned}
$$

subject to

$$
c=\Psi(1, k)\left[Y\left(l, 0 ; x_{i}, 0\right)-d\right]=\Psi(1, k)\left[x_{i} l-d\right]
$$

and

$$
e=Q(t, d, k)
$$

In the above problem, $\beta$ is the discount factor. Here $\Omega_{2}\left(z_{l}\right) \Gamma\left(\gamma_{n}\right)$ gives the probability that a single female will meet a single male of type $z_{l}$ and that their match will be of quality $\gamma_{n}$. Note that $W_{2}\left(x_{k}, z_{l}, \gamma_{n}, k\right)$ is given by the solution to the Nash bargaining problem $\mathrm{P}(3)$ for a type- $\left(x_{k}, z_{l}, \gamma_{n}, k\right)$ marriage. Marriage is an option only if both parties agree, that is, when $I_{2}^{s}\left(x_{k}, z_{l}, \gamma_{n}, k\right)=1$; see $\mathrm{P}(4)$. The value $G_{2}\left(x_{k}, k, 0\right)$ of remaining single is given by the solution to the problem of an old single female, or by $\mathrm{P}(1)$. Last, note that in $\mathrm{P}(5)$ the indicator function $I_{2}^{s}\left(x_{k}, z_{l}, \gamma_{n}, k\right)$ chooses married or single life for the female when old depending upon what is 
in her best interest to do. Married life must also be feasible in the sense that her mate must agree. ${ }^{6}$ This is incorporated into the indicator function's construction.

Let the utility-maximizing decision rules for the quantity and quality of children that solve this problem be represented by

$$
k=K^{s}\left(x_{i}\right)
$$

and

$$
e=E_{1}^{s}\left(x_{i}\right)
$$

The analogous recursion for a single male is

$$
\begin{aligned}
\mathrm{P}(6) \quad B_{1}\left(z_{j}\right)=\max _{n}\{ & M(c, 0,0,1-n) \\
& +\beta \sum_{l=1}^{S} \sum_{i=1}^{S} \sum_{k=0}^{K} \sum_{n=1}^{m}\left\{H_{2}\left(x_{i}, z_{l}, \gamma_{n}, k\right) I_{2}^{s}\left(x_{i}, z_{l}, \gamma_{n}, k\right)\right. \\
& \left.\left.+B_{2}\left(z_{l}, 0\right)\left[1-I_{2}^{s}\left(x_{i}, z_{l}, \gamma_{n}, k\right)\right]\right\} \Phi_{2}\left(x_{i}, k\right) \Gamma\left(\gamma_{n}\right) Z\left(z_{l} \mid z_{j}\right)\right\}
\end{aligned}
$$

subject to

$$
c=\Psi(1,0) Y\left(0, n ; 0, z_{j}\right)=z_{j} n
$$

where $\Phi_{2}\left(x_{i}, k\right) \Gamma\left(\gamma_{n}\right)$ is the probability of meeting an old single female of type- $x_{i}$ with $k$ children and having a match quality of $\gamma_{n}$.

\subsection{Household Activity-Young Married Adults}

Nash bargaining problem: Consider now the problem of a young married couple. Applying the Nash bargaining solution to the fixed-threat bargaining game facing a young couple in a type- $\left(x_{i}, z_{j}, \gamma_{h}\right)$ marriage gives

$\mathrm{P}(7)$

$$
\begin{aligned}
& \max _{l, n, t, d, k}\left\{\left\{F(c, e, k, 1-l-t)+\beta \sum_{v=1}^{S} \sum_{l=1}^{S} \sum_{n=1}^{m}\left[W_{2}\left(x_{v}, z_{l}, \gamma_{n}, k\right) I_{2}^{m}\left(x_{v}, z_{l}, \gamma_{n}, k\right)\right.\right.\right. \\
& \left.\left.+G_{2}\left(x_{v}, k, z_{l}\right)\left[1-I_{2}^{m}\left(x_{v}, z_{l}, \gamma_{n}, k\right)\right]\right] \Delta\left(\gamma_{n} \mid \gamma_{h}\right) X\left(x_{v} \mid x_{i}\right) Z\left(z_{l} \mid z_{j}\right)-G_{1}\left(x_{i}\right)\right\}
\end{aligned}
$$

${ }^{6}$ That is, here there is a bilateral search problem, as opposed to the more typical unilateral jobsearch model, say as typified by the Andolfatto and Gomme (1996) and Hansen and Imrohoroglu (1992) analyses of unemployment insurance. 


$$
\begin{aligned}
& \times\left\{M(c, e, k, 1-n)+\beta \sum_{v=1}^{S} \sum_{l=1}^{S} \sum_{n=1}^{m}\left[H_{2}\left(x_{v}, z_{l}, \gamma_{n}, k\right) I_{2}^{m}\left(x_{v}, z_{l}, \gamma_{n}, k\right)\right.\right. \\
& \left.\left.\left.+B_{2}\left(z_{l}, k\right)\left[1-I_{2}^{m}\left(x_{v}, z_{l}, \gamma_{n}, k\right)\right]\right] \Delta\left(\gamma_{n} \mid \gamma_{h}\right) X\left(x_{v} \mid x_{i}\right) Z\left(z_{l} \mid z_{j}\right)-B_{1}\left(z_{j}\right)\right\}\right\}
\end{aligned}
$$

subject to

$$
c=\Psi(2, k)\left[Y\left(l, n ; x_{i}, z_{j}\right)-d\right]-\gamma_{h}=\Psi(2, k)\left[x_{i} l+z_{j} n-d\right]-\gamma_{h}
$$

and

$$
e=Q(t, d, k)
$$

The threat points $G_{1}\left(x_{i}\right)$ and $B_{1}\left(z_{j}\right)$ are given by the solutions to the problems for young single females and males.

Let the optimal decision rules for the quantity and quality of children in a type- $\left(x_{i}, z_{j}, \gamma_{h}\right)$ young marriage be denoted by

$$
k=K^{m}\left(x_{i}, z_{j}, \gamma_{n}\right)
$$

and

$$
e=E_{1}^{m}\left(x_{i}, z_{j}, \gamma_{h}\right)
$$

Furthermore, let the expected lifetime utility for a young male and female arising out of a type- $\left(x_{i}, z_{j}, \gamma_{h}\right)$ marriage be represented by

$$
H_{1}\left(x_{i}, z_{j}, \gamma_{h}\right)
$$

and

$$
W_{1}\left(x_{i}, z_{j}, \gamma_{h}\right)
$$

3.6. Marriage-Young Adults. The marriage decision for a randomly matched young couple, $(x, z, \gamma)$, is given by

$\mathrm{P}(8) \quad I_{1}^{s}(x, z, \gamma)= \begin{cases}1, & \text { if } W_{1}(x, z, \gamma) \geq G_{1}(x) \quad \text { and } \quad H_{1}(x, z, \gamma) \geq B_{1}(z) \\ 0, & \text { otherwise }\end{cases}$ 


\section{STATIONARY EQUILIBRIUM}

4.1. Steady-State Population Growth. The average number of children per female, $\mathbf{k}$, is given by

$$
\begin{aligned}
\mathbf{k}= & \sum_{i=1}^{S} \sum_{j=1}^{S} \sum_{h=1}^{m} \Phi_{1}\left(x_{i}\right) \Omega_{1}\left(z_{j}\right) \Gamma\left(\gamma_{h}\right) I_{1}^{S}\left(x_{i}, z_{j}, \gamma_{h}\right) K^{m}\left(x_{i}, z_{j}, \gamma_{h}\right) \\
& +\sum_{i=1}^{S} \Phi_{1}\left(x_{i}\right)\left[1-\sum_{j=1}^{S} \sum_{h=1}^{m} \Omega_{1}\left(z_{j}\right) \Gamma\left(\gamma_{h}\right) I_{1}^{S}\left(x_{i}, z_{j}, \gamma_{h}\right)\right] K^{s}\left(x_{i}\right)
\end{aligned}
$$

To understand this formula, note that the probability of a type- $\left(x_{i}, z_{j}, \gamma_{h}\right)$ marriage between young adults is $\Phi_{1}\left(x_{i}\right) \Omega_{1}\left(z_{j}\right) \Gamma\left(\gamma_{h}\right) I_{1}^{s}\left(x_{i}, z_{j}, \gamma_{h}\right)$. This match will generate $K^{m}\left(x_{i}, z_{j}, \gamma_{h}\right)$ kids. The odds that a woman will be type $x_{i}$ and remain single are $\Phi_{1}\left(x_{i}\right)\left[1-\sum_{j=1}^{S} \sum_{h=1}^{m} \Omega_{1}\left(z_{j}\right) \Gamma\left(\gamma_{h}\right) I_{1}^{s}\left(x_{i}, z_{j}, \gamma_{h}\right)\right]$. This woman will have $K^{s}\left(x_{i}\right)$ children. In a stationary equilibrium the growth rate of the population, $g$, will therefore be

$$
g=\sqrt{\frac{\mathbf{k}}{2}}
$$

\subsection{Steady-State Matching Probabilities}

Young adults: The probabilities of meeting a young female and male of a given type in the marriage market are $\Phi_{1}(x)$ and $\Omega_{1}(z)$. To determine these probabilities, let $\Upsilon^{m m}\left(x_{i}, z_{j}, \gamma_{h}, x_{k}, z_{l}, \gamma_{n}\right)$ represent the fraction of females who were married in both periods and transited from state $\left(x_{i}, z_{j}, \gamma_{h}\right)$ to $\left(x_{k}, z_{l}, \gamma_{n}\right)$. Likewise, let $\Upsilon^{s s}\left(x_{i}, x_{k}\right)$ denote the fraction of females who were single in both periods, and transited from $x_{i}$ to $x_{k}$, and $\Upsilon^{m s}\left(x_{i}, z_{j}, \gamma_{h}, x_{k}, z_{l}\right)$ denote the fraction of females who suffered a marriage breakup, etc. Hence,

$$
\begin{aligned}
& \Upsilon^{m m}\left(x_{i}, z_{j}, \gamma_{h}, x_{k}, z_{l}, \gamma_{n}\right) \equiv \Phi_{1}\left(x_{i}\right) \Omega_{1}\left(z_{j}\right) \Gamma\left(\gamma_{h}\right) I_{1}^{s}\left(x_{i}, z_{j}, \gamma_{h}\right) \\
& \times I_{2}^{m}\left(x_{k}, z_{l}, \gamma_{n}, k^{m}\right) \Delta\left(\gamma_{n} \mid \gamma_{h}\right) X\left(x_{k} \mid x_{i}\right) Z\left(z_{l} \mid z_{j}\right) \\
& \Upsilon^{s s}\left(x_{i}, x_{k}\right) \equiv \Phi_{1}\left(x_{i}\right)\left[1-\sum_{j=1}^{S} \sum_{h=1}^{m} \Gamma\left(\gamma_{h}\right) \Omega_{1}\left(z_{j}\right) I_{1}^{s}\left(x_{i}, z_{j}, \gamma_{h}\right)\right] \\
& \times X\left(x_{k} \mid x_{i}\right)\left[1-\sum_{l=1}^{S} \sum_{n=1}^{m} \Gamma\left(\gamma_{n}\right) I_{2}^{s}\left(x_{k}, z_{l}, \gamma_{n}, k^{s}\right) \Omega_{2}\left(z_{l}\right)\right] \\
& \Upsilon^{m s}\left(x_{i}, z_{j}, \gamma_{h}, x_{k}, z_{l}\right) \equiv \Phi_{1}\left(x_{i}\right) \Omega_{1}\left(z_{j}\right) \Gamma\left(\gamma_{h}\right) I_{1}^{s}\left(x_{i}, z_{j}, \gamma_{h}\right) X\left(x_{k} \mid x_{i}\right) Z\left(z_{l} \mid z_{j}\right) \\
& \times\left\{\sum_{n=1}^{m} \Delta\left(\gamma_{n} \mid \gamma_{h}\right)\left[1-I_{2}^{m}\left(x_{k}, z_{l}, \gamma_{n}, k^{m}\right)\right]\right\}
\end{aligned}
$$




$$
\begin{aligned}
\Upsilon^{s m}\left(x_{i}, x_{k}, z_{l}, \gamma_{n}\right) \equiv & \Phi_{1}\left(x_{i}\right)\left[1-\sum_{j=1}^{S} \sum_{h=1}^{m} \Gamma\left(\gamma_{h}\right) \Omega_{1}\left(z_{j}\right) I_{1}^{s}\left(x_{i}, z_{j}, \gamma_{h}\right)\right] \\
& \times I_{2}^{s}\left(x_{k}, z_{l}, \gamma_{n}, k^{s}\right) \Gamma\left(\gamma_{n}\right) X\left(x_{k} \mid x_{i}\right) \Omega_{2}\left(z_{l}\right)
\end{aligned}
$$

where $k^{m} \equiv K^{m}\left(x_{i}, z_{j}, \gamma_{h}\right)$ and $k^{s} \equiv K^{s}\left(x_{i}\right)$.

Then, it is easy to see that the odds of meeting a young woman of type $x_{r}$ in the marriage market are given by

(3) $\Phi_{1}\left(x_{r}\right)=\left\{\sum_{i, j, k, l, h, n} \Xi\left(x_{r} \mid E_{1}^{m}\left(x_{i}, z_{j}, \gamma_{h}\right)+E_{2}^{m}\left(x_{k}, z_{l}, \gamma_{n}, K^{m}\left(x_{i}, z_{j}, \gamma_{h}\right)\right)\right)\right.$

$$
\begin{aligned}
& \times \Upsilon^{m m}\left(x_{i}, z_{j}, \gamma_{h}, x_{k}, z_{l}, \gamma_{n}\right) K^{m}\left(x_{i}, z_{j}, \gamma_{h}\right) \\
& +\sum_{i, k} \Xi\left(x_{r} \mid E_{1}^{s}\left(x_{i}\right)+E_{2}^{s}\left(x_{k}, K^{s}\left(x_{i}\right), 0\right)\right) \Upsilon^{s s}\left(x_{i}, x_{k}\right) K^{s}\left(x_{i}\right) \\
& +\sum_{i, j, k, l, h} \Xi\left(x_{r} \mid E_{1}^{m}\left(x_{i}, z_{j}, \gamma_{h}\right)+E_{2}^{s}\left(x_{k}, K^{m}\left(x_{i}, z_{j}, \gamma_{h}\right), z_{l}\right)\right) \\
& \times \Upsilon^{m s}\left(x_{i}, z_{j}, \gamma_{h}, x_{k}, z_{l}\right) K^{m}\left(x_{i}, z_{j}, \gamma_{h}\right) \\
& +\sum_{i, k, l, n} \Xi\left(x_{r} \mid E_{1}^{s}\left(x_{i}\right)+E_{2}^{m}\left(x_{k}, z_{l}, \gamma_{n}, K^{s}\left(x_{i}\right)\right)\right) \\
& \left.\times \Upsilon^{s m}\left(x_{i}, x_{k}, z_{l}, \gamma_{n}\right) K^{s}\left(x_{i}\right)\right\} / \mathbf{k}
\end{aligned}
$$

The probability of meeting a type- $z_{r}$ young man is determined analogously:

$$
\begin{aligned}
\Omega_{1}\left(z_{r}\right)= & \left\{\sum_{i, j, k, l, h, n} \Lambda\left(z_{r} \mid E_{1}^{m}\left(x_{i}, z_{j}, \gamma_{h}\right)+E_{2}^{m}\left(x_{k}, z_{l}, \gamma_{n}, K^{m}\left(x_{i}, z_{j}, \gamma_{h}\right)\right)\right)\right. \\
& \times \Upsilon^{m m}\left(x_{i}, z_{j}, \gamma_{h}, x_{k}, z_{l}, \gamma_{n}\right) K^{m}\left(x_{i}, z_{j}, \gamma_{h}\right) \\
& +\sum_{i, k} \Lambda\left(z_{r} \mid E_{1}^{s}\left(x_{i}\right)+E_{2}^{s}\left(x_{k}, K^{s}\left(x_{i}\right), 0\right)\right) \Upsilon^{s s}\left(x_{i}, x_{k}\right) K^{s}\left(x_{i}\right) \\
& +\sum_{i, j, k, l, h} \Lambda\left(z_{r} \mid E_{1}^{m}\left(x_{i}, z_{j}, \gamma_{h}\right)+E_{2}^{s}\left(x_{k}, K^{m}\left(x_{i}, z_{j}, \gamma_{h}\right), z_{l}\right)\right) \\
& \times \Upsilon^{m s}\left(x_{i}, z_{j}, \gamma_{h}, x_{k}, z_{l}\right) K^{m}\left(x_{i}, z_{j}, \gamma_{h}\right) \\
& +\sum_{i, k, l, n} \Lambda\left(z_{r} \mid E_{1}^{s}\left(x_{i}\right)+E_{2}^{m}\left(x_{k}, z_{l}, \gamma_{n}, K^{s}\left(x_{i}\right)\right)\right) \\
& \left.\times \Upsilon^{s m}\left(x_{i}, x_{k}, z_{l}, \gamma_{n}\right) K^{s}\left(x_{i}\right)\right\} / \mathbf{k}
\end{aligned}
$$

Old adults: Next, how are the odds of meeting a single age-2 type- $x$ female with $k$ children, $\Phi_{2}(x, k)$, or of a single age- 2 type- $z$ male, $\Omega_{2}(z)$ determined in stationary equilibrium? This depends upon the number of single agents who remain unmarried from the previous period. So, how many are 
there? Again, the numbers of married and single one-period-old type- $x_{i}$ females are given by $\Phi_{1}\left(x_{i}\right) \sum_{j=1}^{S} \sum_{h=1}^{m} \Omega_{1}\left(z_{j}\right) \Gamma\left(\gamma_{h}\right) I_{1}^{s}\left(x_{i}, z_{j}, \gamma_{h}\right)$ and $\Phi_{1}\left(x_{i}\right)[1-$ $\left.\sum_{j=1}^{S} \sum_{h=1}^{m} \Omega_{1}\left(z_{j}\right) \Gamma\left(\gamma_{h}\right) I_{1}^{S}\left(x_{i}, z_{j}, \gamma_{h}\right)\right]$. Given this supply of one-period-old single females, the quantity of two-period-old type- $x_{k}$ single females will be $\sum_{i=1}^{S} X\left(x_{k} \mid x_{i}\right) \Phi_{1}\left(x_{i}\right)\left[1-\sum_{j=1}^{S} \sum_{h=1}^{m} \Omega_{1}\left(z_{j}\right) \Gamma\left(\gamma_{h}\right) I_{1}^{S}\left(x_{i}, z_{j}, \gamma_{h}\right)\right]$.

Let

$$
\mathfrak{N}\left(x_{i}, k\right)= \begin{cases}1, & \text { if } K^{s}\left(x_{i}\right)=k \\ 0, & \text { otherwise }\end{cases}
$$

be an indicator function representing the number of children that a single oneperiod-old female of type $x_{i}$ has. Then, the odds of drawing a single two-period-old type- $x_{k}$ female with $k$ children in the marriage market, or $\Phi_{2}\left(x_{k}, k\right)$, will be given by

$$
\begin{aligned}
& \Phi_{2}\left(x_{k}, k\right) \\
& \quad=\frac{\sum_{i=1}^{S} \mathfrak{N}\left(x_{i}, k\right) X\left(x_{k} \mid x_{i}\right) \Phi_{1}\left(x_{i}\right)\left[1-\sum_{j=1}^{S} \sum_{h=1}^{m} \Gamma\left(\gamma_{h}\right) \Omega_{1}\left(z_{j}\right) I_{1}^{s}\left(x_{i}, z_{j}, \gamma_{h}\right)\right]}{\sum_{k=1}^{S} \sum_{i=1}^{S} X\left(x_{k} \mid x_{i}\right) \Phi_{1}\left(x_{i}\right)\left[1-\sum_{j=1}^{S} \sum_{h=1}^{m} \Gamma\left(\gamma_{h}\right) \Omega_{1}\left(z_{j}\right) I_{1}^{S}\left(x_{i}, z_{j}, \gamma_{h}\right)\right]}
\end{aligned}
$$

The analogous formula for the odds of meeting a single two-period-old male of type $z_{l}$, or for $\Omega_{2}\left(z_{l}\right)$, reads

$$
\Omega_{2}\left(z_{l}\right)=\frac{\sum_{j=1}^{S} Z\left(z_{l} \mid z_{j}\right) \Omega_{1}\left(z_{j}\right)\left[1-\sum_{i=1}^{S} \sum_{h=1}^{m} \Gamma\left(\gamma_{h}\right) \Phi_{1}\left(x_{i}\right) I_{1}^{S}\left(x_{i}, z_{j}, \gamma_{h}\right)\right]}{\sum_{l=1}^{S} \sum_{j=1}^{S} Z\left(z_{l} \mid z_{j}\right) \Omega_{1}\left(z_{j}\right)\left[1-\sum_{i=1}^{S} \sum_{h=1}^{m} \Gamma\left(\gamma_{h}\right) \Phi_{1}\left(x_{i}\right) I_{1}^{S}\left(x_{i}, z_{j}, \gamma_{h}\right)\right]}
$$

It's now time to take stock of the situation so far.

Definition 1. A stationary matching equilibrium can be represented by a set of child quantity and quality allocation rules, $K^{m}(x, z, \gamma), K^{s}(x)$, $E_{2}^{m}(x, z, \gamma, k), E_{2}^{s}(x, k, z), E_{1}^{m}(x, z, \gamma)$, and $E_{1}^{s}(x)$, a set of marriage decision rules, $I_{2}^{m}(x, z, \gamma, k), I_{2}^{s}(x, z, \gamma, k)$, and $I_{1}^{s}(x, z, \gamma)$, and a set of matching probabilities, $\Phi_{1}(x), \Phi_{2}(x, k), \Omega_{1}(z)$, and $\Omega_{2}(z)$, such that:

1. The child quality allocation rule $E_{2}^{s}(x, k, z)$ solves the old single female's household problem $\mathrm{P}(1)$.

2. The child quantity and quality allocation rules $K^{s}(x)$ and $E_{1}^{s}(x)$ solve the young single female's household problem $\mathrm{P}(5)$.

3 . The child quality allocation rule $E_{2}^{m}(x, z, \gamma, k)$ solves the married old couple's Nash bargaining problem $\mathrm{P}(3)$.

4. The child quantity and quality allocation rules $K^{m}(x, z, \gamma)$ and $E_{1}^{m}(x, z, \gamma)$ solve the young married couple's Nash bargaining problem $\mathrm{P}(7)$.

5. The marriage decisions for old couples, who either begin the second period married or start the period single and meet on the marriage market, 
TABLE 1

BENCHMARK PARAMETER VALUES

\begin{tabular}{lll}
\hline & \multicolumn{1}{c}{ Parameter Values } & \multicolumn{1}{c}{ Criteria } \\
\hline Tastes & $\beta=0.67$ & A priori information \\
& $v=0.5, \xi=0.325, \vartheta_{f}=0.2, \vartheta_{m}=0.35$ & Free-fertility \\
& $\delta=3, \varsigma=0.3$ & Free-time allocations \\
Technology & $b=0.3, \eta=0.5$ & A priori information \\
& $\iota=0.05, \iota_{m}=0.0325$ & Free-fertility \\
& $\alpha=0.5, \kappa_{1}=0.4, \kappa_{2}=0.5$ & Free-investment in kids \\
Shocks & $\varepsilon_{1}=15.15, \varepsilon_{2}=0.5, \mu=4.17$ & Free-income distribution \\
& $\sigma_{x \mid e}=\sigma_{x \mid e}=0.4$ & Free-income distribution \\
& $\mu_{x}=2.2, \mu_{z}=2.58, \sigma=0.57, \rho_{x}=0.7, \rho_{z}=0.7$ & Free-income distribution \\
& $\gamma_{1}=2.5, \gamma_{2}=0$ & Free-marital status \\
& $\Gamma\left(\gamma_{1}\right)=\Gamma\left(\gamma_{2}\right)=0.5, \Delta\left(\gamma_{1} \mid \gamma_{1}\right)=\Delta\left(\gamma_{2} \mid \gamma_{2}\right)=0.5$ & Free-marital status \\
Policy variables & $a=0.05$ & A priori information \\
\hline
\end{tabular}

$I_{2}^{m}(x, z, \gamma, k)$ and $I_{2}^{s}(x, z, \gamma, k)$, are described by $\mathrm{P}(4)$, in conjunction with $\mathrm{P}(1), \mathrm{P}(2)$, and $\mathrm{P}^{\prime}(3)$.

6. The marriage decision for a young couple, $I_{1}^{s}(x, z, \gamma)$, is described by $\mathrm{P}(8)$, in conjunction with $\mathrm{P}(5), \mathrm{P}(6)$, and $\mathrm{P}^{\prime}(7)$.

7. The matching probabilities, $\Phi_{1}(x), \Phi_{2}(x, k), \Omega_{1}(z)$, and $\Omega_{2}(z)$, are governed by the stationary distributions described by (3) to (4).

At a general level, not much can be said about the properties of the above model since the solution involves a complicated fixed-point problem. On the one hand, in order to compute the solution to a young single agent's choice problem one needs to know the equilibrium matching probabilities. On the other hand, calculating the equilibrium matching probabilities requires knowledge about the solutions to each of the decision problems.

\section{SOME COMPUTATIONAL ANALYSIS}

5.1. Benchmark Equilibrium. To gain some insight into the model's mechanics, its solution will be computed numerically. ${ }^{7}$ To do this, values must be assigned to the model's parameters. The parameter values are listed in Table 1 . The simulation results should be viewed more as an extension of the pencil-and-paper techniques employed in economic theory, to explore the properties of a model, as opposed to a data-fitting exercise. Separate sets of 15 points are chosen for each gender's productivity levels (so that $S=15$ ). There are two possible match values (implying $m=2$ ). Each female was restricted to have no more than four kids (i.e., $K=4) .{ }^{8}$ Finally, take a model period to be 10 years.

\footnotetext{
${ }^{7}$ The algorithm for finding the equilibrium type distributions, or the $\Phi$ 's and $\Omega$ 's, is similar to that employed in Aiyagari et al. (2000). For more detail, see that source.

${ }^{8}$ The constraint $K=4$ was nonbinding, i.e., letting $K=5$ did not affect people's fertility decisions.
} 
5.1.1. Parameter values. In order to simulate the model, values must be assigned to the model's various parameters. For a model like this, almost nothing is known about the appropriate choice of parameter values or functional forms. For the most part, parameter values are not chosen to tune the model to be in perfect harmony with any particular observations. Instead, they are picked to generate an equilibrium that displays several interesting features that are in rough accord with data. The developed model is still too primitive to confront the data in a serious manner. Yet, as will be seen, it does show promise. Table 1 lists the parameter values used in the analysis. A guide to the informal procedure used to pick parameter values will now be given. Essentially, each parameter is connected to a data category, specifically, the category where the parameter's influence on the model's output is felt the heaviest. The parameter's impact on this set of observations is used as a guide to choose the value for the parameter. Needless to say, however, things are not quite this simple. In a general equilibrium model such as this each parameter can affect all of the endogenous variables. The selection scheme is as follows:

1. A priori information: A few parameters values can be taken directly from the literature.

a. There is a large set of available estimates for $b$ and $\eta$, the parameters that govern congestion in household consumption. Cutler and Katz (1992) report $\eta=0.5$ as an intermediate estimate. For the parameter $b$, Browning (1992) gives a wide array of estimates, ranging from 0.12 to 1 . Again, take $b=0.3$ as an intermediate value.

b. The policy parameter $a$, or the amount of support payment per child, can be determined from the available evidence. Child support guidelines are determined at the state level and can be quite complicated (see Garfinkel and Oellerich, 1989). A simple rule is the one adopted by Wisconsin. It states that a father has to pay, as child support payment after divorce, 17,25 , or $29 \%$ of his gross income for one, two, or three children, respectively. This is not the whole story, however, since between 1993 and 1997 only about $40 \%$ of custodial mothers received any child support payments (Grall, 2000). So, if the Wisconsin rule is costed out for two children (the average number of children in the benchmark economy) and adjusted for the fraction of custodial mothers who do not receive any child support, then $5 \%$ of the father's income is a realistic number for child support payments in the economy.

c. The discount factor, $\beta$, is chosen to reflect a $4 \%$ yearly interest rate, say, as in Kydland and Prescott (1982).

2. Free parameters: These parameters are chosen to influence the model's performance along some dimension. In particular, the model's performance along each of the following data categories is used as guiding principle to pick a particular set of parameters as indicated below. Utility parameters for males and females are kept symmetric, except for the 
TABLE 2

THE MARITAL STATUS OF MOTHERS, MODEL (PERCENTAGE DISTRIBUTION)

\begin{tabular}{lcr}
\hline & Young & Old \\
\hline Married & 86 & 85 \\
Single & 14 & 5 \\
Divorced & - & 10 \\
\hline
\end{tabular}

utility parameters that govern the quality of children. The fixed costs of raising children are also taken to be different for females and males. ${ }^{9}$

a. Marital status of mothers: $\gamma_{1}, \gamma_{2}, \Gamma\left(\gamma_{1}\right), \Gamma\left(\gamma_{2}\right), \Delta\left(\gamma_{1} \mid \gamma_{1}\right)$, and $\Delta\left(\gamma_{2} \mid \gamma_{2}\right)$.

b. Time allocations: $\varsigma_{f}=\varsigma_{m}=\varsigma$ and $\delta_{f}=\delta_{m}=\delta$.

c. Fertility: $v_{f}=v_{m}=v, \xi_{f}=\xi_{m}=\xi, \vartheta_{f}, \vartheta_{m}, \iota_{f}$, and $\iota_{m}$.

d. Distribution of income: $\varepsilon_{1}, \varepsilon_{2}, \mu, \sigma_{x \mid e}, \sigma_{z \mid e}, \mu_{x}, \mu_{z}, \sigma, \rho_{x}$, and $\rho_{z}$.

e. Investment in children: $\alpha, \kappa_{1}$, and $\kappa_{2}$.

Each of these will now be discussed in more detail.

5.1.2. The marital status of mothers. As Table 2 shows, at any point in time a significant proportion of the adult population in the model is not married. In equilibrium some people are always single, others experience a divorce. About $85 \%$ of the population is married. How does this compare with the data? All females (single and married) choose to have children in the benchmark economy. Hence, one way to judge the performance of the model is to look at the distribution of families with children headed by either a married couple or a lone single female. In the United States between 1970 and 1999, about 82\% of families with children were made up by married couples, with the remaining $18 \%$ consisting of femaleheaded ones (U.S. Bureau of the Census, 2000). In the benchmark economy, about $85 \%$ of families consist of married couples and $15 \%$ of them are headed by single females, not very far off from the data. ${ }^{10}$

5.1.3. Time allocations. Time allocations across agents in the model are shown in Table 3. As guidance for the two parameters that govern utility from leisure, the labor supply of married men relative to married women and single men is

\footnotetext{
${ }^{9}$ While differences in the fixed time cost of raising children is not very controversial, one might question if men and women care differently about the quality of their children. Evidence from household surveys indicate that this might, indeed, be the case. When women have more resources in households, expenditure patterns are usually tilted toward children's goods (see, for example, Attanasio and Lechene, 2002).

${ }^{10}$ Another way to cut the data would be to look at the marital distribution of the female population. Between 1970 and 1999, about $75 \%$ of the population above age 20 was married, roughly $9 \%$ was divorced, and approximately $16 \%$ had never been married. In the benchmark economy less people never get married $(10 \%)$ while more people tie the knot $(85 \%)$. This is not surprising, since in the model people have only one chance of matching each period. This promotes early marriage. The setup also abstracts from important factors that delay marriage and fertility, such as the decision to go to college.
} 
TABLE 3

TIME ALLOCATIONS, MODEL

\begin{tabular}{llllllll}
\hline & \multicolumn{3}{c}{ Male } & & \multicolumn{3}{c}{ Female } \\
\cline { 2 - 3 } & Married & Single & Divorced & & Married & Single & Divorced \\
\hline Work & 0.60 & 0.44 & 0.41 & & 0.37 & 0.27 & 0.27 \\
Nurture & 0 & 0 & 0 & & 0.21 & 0.10 & 0.10 \\
Leisure & 0.34 & 0.56 & 0.59 & & 0.33 & 0.46 & 0.52 \\
Fixed & 0.06 & 0 & 0 & & 0.09 & 0.17 & 0.12 \\
\hline
\end{tabular}

loosely targeted. ${ }^{11}$ In the model economy, married males work more than married females and unmarried males. A married man works about $62 \%$ more than a married female, and about $40 \%$ more than a single male. ${ }^{12}$ This pattern is also true in the data: in the PSID for 1990, married men between ages 20 and 39 worked about $80 \%$ more than married women with children (and about $62 \%$ more than married women as taken as a whole), and about $34 \%$ more than single men. (The numbers reported by McGratten and Rogerson, 1998 using the Current Population Survey (CPS) are very similar.) While the model matches these two aspects of the data, qualitatively, married mothers work more than single ones in the model (about $37 \%$ more). In the data married mothers worked about the same as single mothers. ${ }^{13}$

5.1.4. Fertility. Several parameters are picked to influence fertility behavior in the model. They are chosen: (i) to yield an aggregate fertility level of two kids per female (the total fertility rate has been around 2 in the United States since the early 1970s), (ii) to generate a realistic cross-sectional fertility-income relationship, and (iii) to match the aggregate data on the fraction of children in married-couple and single-female-headed families.

The fertility-income relationship: Figure 1 shows the relationship between income and family size for both the model and the United States. The data for the United States comes from the Panel Study on Income Dynamics (PSID). The earnings variable is the present value of future lifetime household labor income at age 30, as calculated by Knowles (1999). In the data, fertility declines with labor income. The fertility variable is total number of children ever born to a woman, who is either head or spouse of the household head. The model replicates this relationship quite well. ${ }^{14}$

\footnotetext{
11 The model's performance along this dimension is not a prime concern of the analysis. For example, Regalia and Ríos-Rull (2001) abstract from labor supply decisions.

${ }^{12}$ Compared with the data, people in the benchmark economy work more. In the model, people work about $46 \%$ of their available nonsleeping time, while the same number in the data is about $27 \%$ (McGratten and Rogerson, 1998).

${ }^{13}$ More generally, in 1990 married women of ages $20-39$ worked about $94 \%$ of the amount worked by single women of the same age group.

${ }^{14}$ One might wonder if the fixed time costs of children that play a key role in the income-fertility relation are reasonable. There are several studies that try to estimate the time cost of children (see Browning, 1992, for a review). Most of these studies, however, do not distinguish between fixed time cost and time for nurture. Robinson (1987) is an exception and reports both physical and nonphysical care. His estimate for the fixed time cost of children is about $3.5 \%$ of nonsleeping time, suggesting that the values for the fixed cost parameters, $\iota_{f}$ and $\iota_{m}$, are not unreasonable.
} 


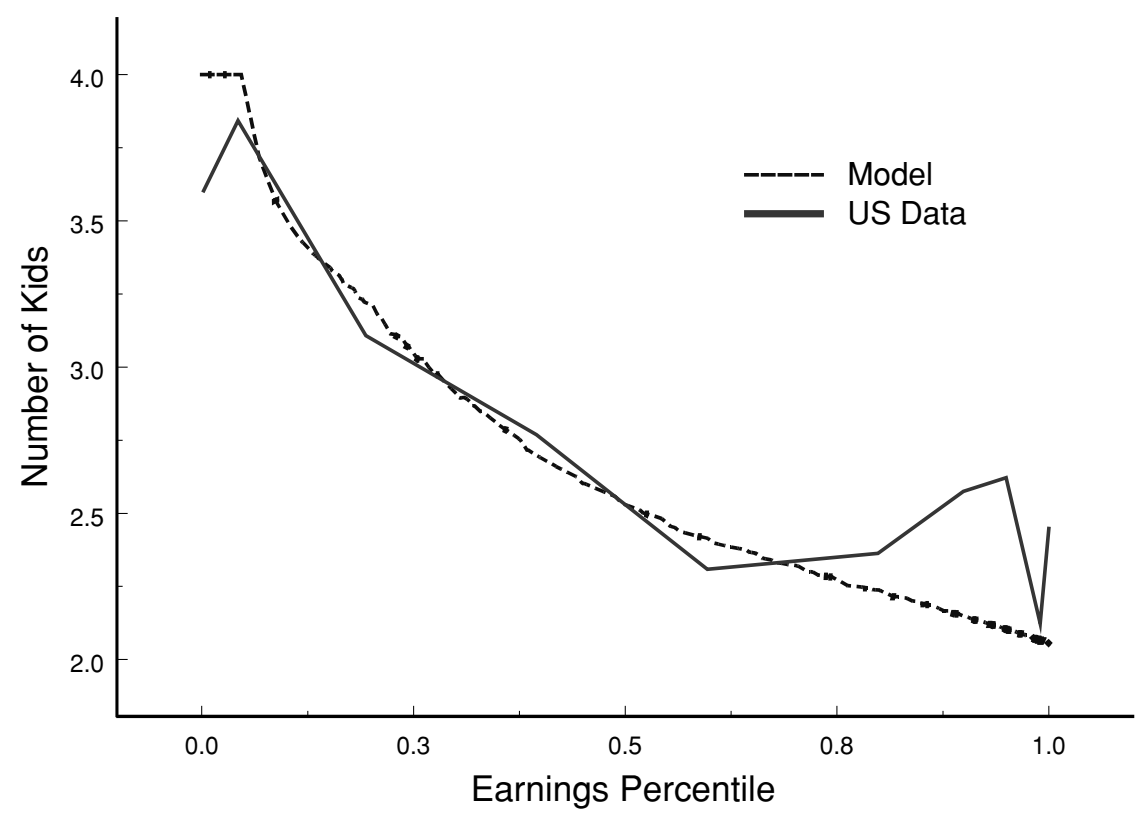

Figure 1

FAMILY INCOME AND THE NUMBER OF KIDS, MODEL AND U.S. DATA

Out-of-wedlock births: In the United States, 22\% of births between 1970 and 1990 were to unmarried mothers. ${ }^{15}$ The model does well on this dimension: $23 \%$ of births are to unwed mothers. More generally, between 1970 and 1990 about 21\% of children in the United States lived with a single mother (either never married or divorced). ${ }^{16}$ The corresponding figure for the model is $22.5 \%$. Since fertility behavior is at the core of the model, however, it might be a worthwhile exercise to have a closer look at other dimensions of fertility behavior that were not used as guidance for picking the parameters.

Further results: Out-of-wedlock births occur disportionately to poorer, lesseducated females. Figure 2 shows the distribution of births by income quintile for various categories of mothers, namely married, never married, and divorced. ${ }^{17}$ The underlying data is taken from the PSID and covers the period 1986-91. ${ }^{18}$ About $20 \%$ of births reported in the PSID are to unmarried women, similar to the national average. Note that the distribution for married women stochastically dominates the distribution for divorced women, which in turn stochastically dominates the one for never-married females. That is, a never-married woman who gives birth

15 Source: Ventura and Bachrach (2000).

${ }^{16}$ U.S. Census Bureau data on the Living Arrangements of Children under 18.

${ }^{17}$ For the latter two categories, the data analysis is restricted to those mothers who report being the head of their household.

${ }^{18}$ More specifically, the raw data is extracted from the PSID Family Panel 1985-1993, Public Release II. 


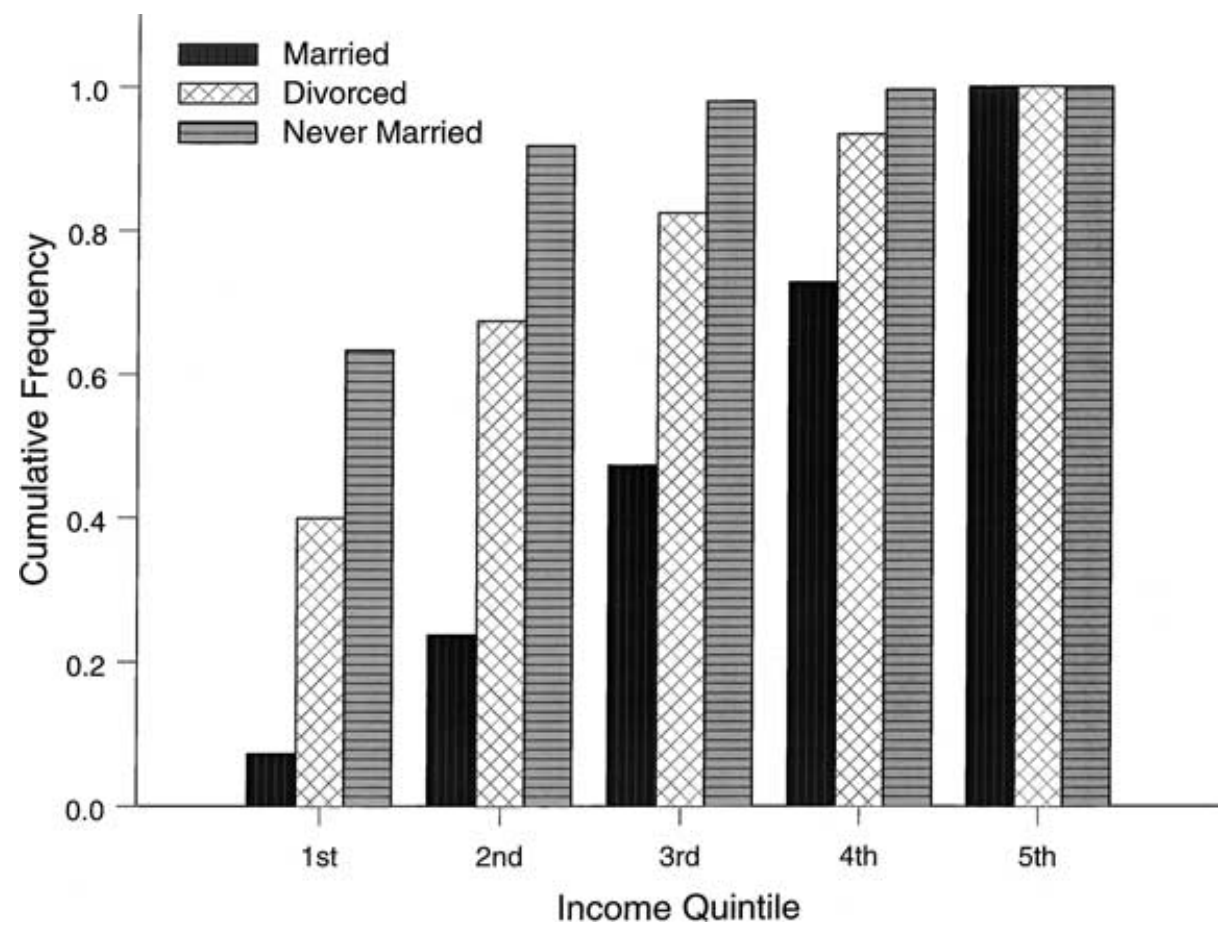

Figure 2

THE DISTRIBUTION OF BIRTHS BY INCOME QUINTILE FOR VARIOUS CATEGORIES OF MOTHERS, U.S. DATA

is much more likely to be poor (from a low income quintile) than a married one. The story is similar when women are categorized by education, as Figure 3 illustrates. Again, the data is from the PSID but now spans the period 1986-93. A never-married female who gives birth is much more likely than is a married one either not to have completed high school or to have no more than a high school education.

Table 4 presents the distribution of births by income quintile that arises in the model for young never-married and married mothers-old women cannot give birth in the model. ${ }^{19}$ As can be seen, the model does remarkably well at matching the distribution of births. For never-married women the model clusters births a bit too much at the low end of the income distribution. The table also breaks down the distribution of births by level of education. Before proceeding, though, a question must be answered: How should education levels in the data be matched with the model? In the PSID about $14.5 \%$ of mothers failed to complete high school, $35.1 \%$ finished high school but went no further with their education, $24.7 \%$ had some education beyond high school but stopped short of a college degree, and

\footnotetext{
${ }^{19}$ There is some slippage between the model and the data. In the model, adults live for only two periods. Hence, a married women can never have suffered through a prior divorce. In the data, this obviously is not true.
} 


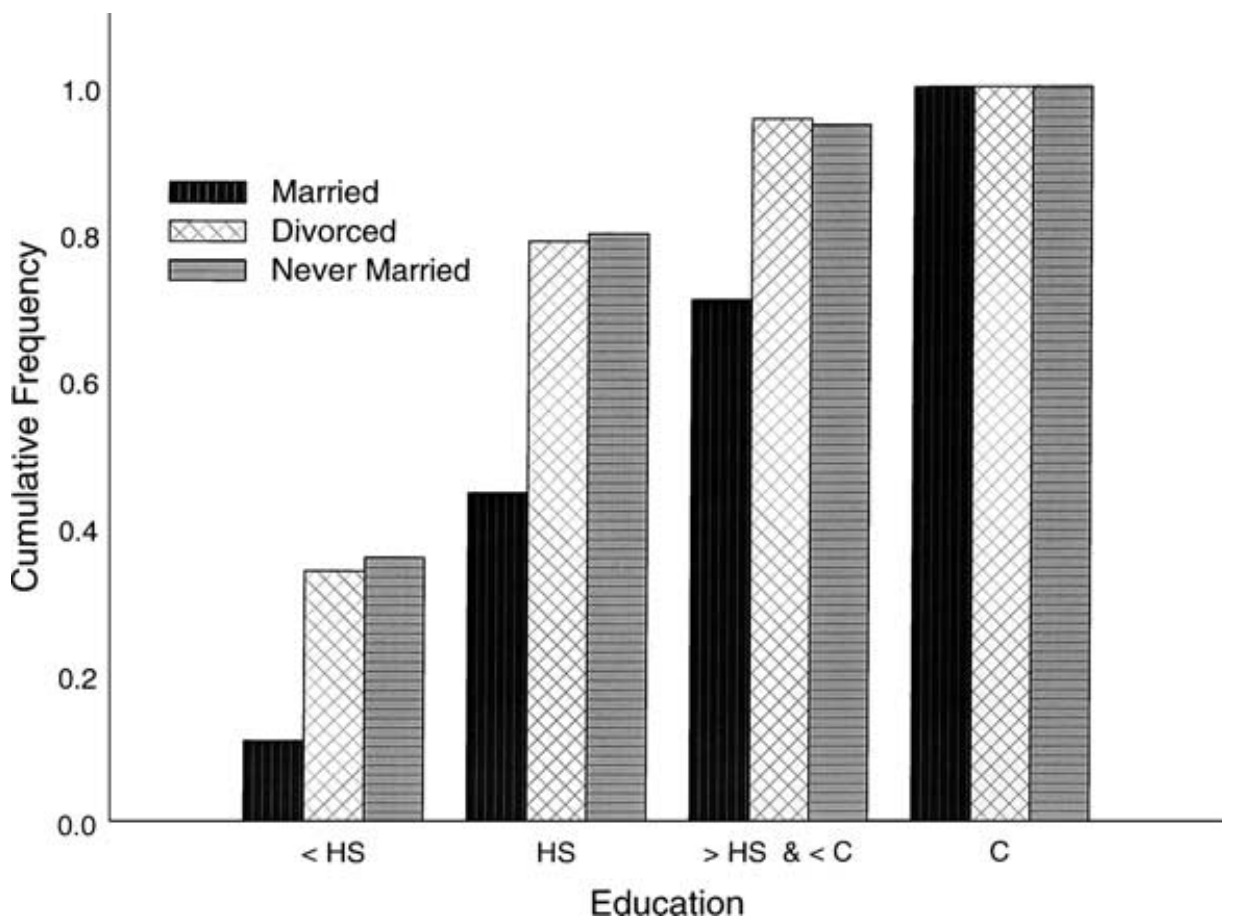

FIGURE 3

THE DISTRIBUTION OF BIRTHS BY EDUCATION FOR VARIOUS CATEGORIES OF MOTHERS, U.S. DATA

$25.7 \%$ graduated from college. To match the theory with the data, order the types in the model from lowest to highest. Call the types making up the first $14.5 \%$ of the model's population a "less than high school education," the types making up the next $35.1 \%$ a "high school education," and so on. The model mimics the distributions of births by education remarkably well. For never-married women, the model lumps too many births at the lowest education level.

Last, in the model, single mothers have a much higher fertility rate than married ones do. A young married mother has 1.8 kids on average, while a young single mother has 3.3. Although the model generates very realistic numbers for the fraction of births that are to unwed mothers and the proportion of children living with a lone mother, the fact that single mothers have more children than married ones can be considered suspicious. So, what do the U.S. data say? Data can be collected from the PSID on the group of women who gave birth in the sample. The PSID reports the birth number associated with each newborn, i.e., the first child, second child, etc. From this, the number of children ever born for married and for never-married mothers can be calculated. On average, never-married mothers have about 2.6 children in contrast to only 2.2 for married women. Most women in the sample are still fertile, however. This needs to be corrected for. One would expect that the number of children a woman has is a nondecreasing, concave function of age. This function should flatten out at about age 44 . 
TABLE 4

DISTRIBUTION OF BIRTHS BY MOTHER'S INCOME AND EDUCATION

\begin{tabular}{|c|c|c|c|c|c|}
\hline \multicolumn{6}{|c|}{ Income } \\
\hline \multirow[b]{2}{*}{ Quintile } & \multicolumn{2}{|r|}{ Data } & & \multicolumn{2}{|c|}{ Model } \\
\hline & Married & Never Married & & Married & Never Married \\
\hline $1 \mathrm{st}$ & 0.073 & 0.633 & & 0.004 & 0.851 \\
\hline 2nd & 0.237 & 0.918 & & 0.229 & 0.974 \\
\hline $3 \mathrm{rd}$ & 0.473 & 0.990 & & 0.486 & 0.993 \\
\hline 4th & 0.728 & 0.996 & & 0.742 & 0.997 \\
\hline 5 th & 1.000 & 1.000 & & 1.000 & 1.000 \\
\hline \multicolumn{6}{|c|}{ Education } \\
\hline & \multicolumn{2}{|r|}{ Data } & & \multicolumn{2}{|c|}{ Model } \\
\hline Level & Married & Never Married & Type & Married & Never Married \\
\hline$<$ H.S. & 0.110 & 0.357 & $1-4$ & 0.094 & 0.449 \\
\hline H.S. & 0.447 & 0.800 & $5-7$ & 0.403 & 0.795 \\
\hline$>$ H.S. \& < C. & 0.710 & 0.948 & $8-9$ & 0.700 & 0.903 \\
\hline C. & 1.000 & 1.000 & $10-15$ & 1.000 & 1.000 \\
\hline
\end{tabular}

To capture this, run a simple regression of the number of children ever born on the age of the mother and its square. To see whether this function differs across married and never-married women, include dummy variables for marital status (which take a value of one for a never-married mother). This gives

$$
\begin{aligned}
& \text { No. of children }=-0.618+\underset{(4.46)}{0.128} * \operatorname{age}-\underset{(-2.10)}{0.001} * \mathrm{age}^{2} \\
& \underset{(-2.08)}{-0.541} * \text { dummy }+\underset{(3.62)}{0.037} * \text { age } * \text { dummy, } \\
& r^{2}=0.14 \quad \text { n.o. }=2,205
\end{aligned}
$$

where the numbers in parentheses are $t$ statistics. All variables are significant and have the expected signs. (Other specifications for the regression yielded similar results. ${ }^{20}$ ) Now, use this regression to predict the number of kids a never-married mother will have by age 44 (at the end of her fertile life). The regression estimates that a never-married mother will have about 3.95 kids, a number a little above model's prediction. The model also underpredicts the number of children that a married mother will have (2.87 versus 1.8$)$. Hence, the model mimics fairly well the fertility gap between married and never married mothers, but tends to underpredict the fertility for both categories of mothers.

\footnotetext{
${ }^{20}$ For instance, the year of birth for each mother was inserted. This controlled for the decline in fertility over the sample period. And, an interactive dummy on the quadratic term was included in some regressions. Never-married mothers had a higher fertility rate than married ones in all specifications run.
} 
TABLE 5

FAMILY INCOME, MODEL

\begin{tabular}{lcc}
\hline & Young & Old \\
\hline Married & 1.00 & 1.00 \\
Single-female & 0.17 & 0.14 \\
Single-male & 0.36 & 0.41 \\
Divorced-female & & 0.24 \\
Divorced-male & & 0.33 \\
\hline
\end{tabular}

5.1.5. The distribution of income. Productivity levels are one of the key determinants of income inequality in the model. In the U.S. data the standard deviation of the log of wages is 0.57 (based on 18-65-year-old nonfarm wage and salary earners in the 1990 PSID data). The parameters $\left(\varepsilon_{1}, \varepsilon_{2}, \mu\right.$ and $\left.\sigma_{x \mid e}=\sigma_{z \mid e}\right)$ that map human capital investment in children, $e_{-2}+e_{-1}$, into the distribution of productivity levels for young adults are chosen to generate roughly the same standard deviation in the (log of the) type distribution. (The grids for $x$ and $z$ are set to span two standard deviations around the means of log wages for women and men. The means are set at 2.2 and 2.58, respectively, an innocuous normalization.) These parameters also generate a very reasonable intergenerational correlation of income. Knowles (1999) finds that the correlation between the lifetime incomes of parents and their sons is about 0.73 . Quite remarkably, the same statistic in the model turns out to be 0.72 .

Family income is also related to marital status, as Table 5 illustrates. ${ }^{21}$ For example, family income for a household headed by a young single female is $17 \%$ of that for a married couple. This transpires for two reasons. To begin with, in a marriage there are two potential wage earners versus only one in a household with a single adult. Additionally, married males and females work more than unmarried ones.

Some income distribution statistics for both the U.S. economy and the model are reported in Table 6 . The figures for the United States are based on a cross section of annual household income for 1992, as reported in the PSID. The table reports the cutoff levels of income corresponding to different percentiles of the income distribution. The number for the 1st percentile is normalized to 1. Hence, in the U.S. data a household that lies at the 5th percentile of the income distribution has an income 2.56 times greater than that of a household that is at the 1st percentile. The corresponding figure for the model is 2.00 . Although the model does a reasonable job matching the data, Table 6 shows that the poor in the model are relatively poorer than in the data, but the rich are not as rich. It is not surprising that the model does not generate enough skewness at the upper end of the income distribution. It does not allow for entrepreneurs, superstars, and other features of

${ }^{21}$ Additionally, in the model, married males tend to earn more than unmarried ones because they make better mates. This is true in the data, too; see Cornwall and Rupert (1997) and Schoeni (1995). In the benchmark economy married males earn about $38 \%$ more than unmarried ones. Although this is a large value for the marriage premium, it is not very far from $30 \%$ estimate provided by Scheoni (1995). 
TABLE 6

INCOME DISTRIBUTION (INCOME LEVEL AT THE CUTOFF (NORMALIZED))

\begin{tabular}{rlr}
\hline Percentile & Data & Model \\
\hline 1 & 1.00 & 1.00 \\
5 & 2.56 & 2.00 \\
10 & 3.85 & 2.84 \\
25 & 7.79 & 6.79 \\
50 & 14.37 & 13.97 \\
75 & 23.44 & 19.58 \\
90 & 34.07 & 25.96 \\
95 & 43.21 & 30.56 \\
99 & 77.5 & 40.92 \\
\hline
\end{tabular}

TABLE 7

FAMILY INCOME PER MEMBER, MODEL

\begin{tabular}{lcc}
\hline & Young & Old \\
\hline Married & 1.00 & 0.97 \\
Single_female & 0.16 & 0.12 \\
Single_male & 1.28 & 1.48 \\
Divorced-female & & 0.26 \\
Divorced-male & & 1.18
\end{tabular}

the labor market. The upshot is that the mean-to-median ratio in the data is 1.26 , as compared with 1.12 in the model.

Furthermore, it makes a difference whether family or per-capita income is used. When family income is adjusted for size, the situation portrayed in Table 5 changes. Single males do relatively better now, since they have no dependents. Perhaps, this is why they work the least. The situation for unmarried females is now even bleaker. Income per family member is only $16 \%$ of the level realized in a married household (see Table 7). The distribution of income is more skewed when income per member is used. The mean-to-median ratio increases from 1.12 to 1.24 in the model. The rise is more modest in the data, from 1.26 to 1.33 . The increase in the model is more significant than the one in data because the number of kids declines a little too sharply with family income (see Figure 1).

5.1.6. Investment in children. Parents spend a significant fraction of their income on children. Olson (1983) provides a detailed analysis of investment on children based on the 1972-73 Consumer Expenditure Survey. His estimates indicate that for a two-parent family with two children, the total cost of these children (other than housing and food) from ages 0 to 22 constitutes about $14 \%$ of the present value of the parents' income. It seems appropriate to focus on expenses other than housing and food, since in the model consumption is a public good with children entering into the congestion function. In the model married households (which have, on average, about two children) spend about $15.5 \%$ of their income 
TABLE 8

INVESTMENT IN HUMAN CAPITAL, MODEL

\begin{tabular}{lcc}
\hline & Young & Old \\
\hline Married & 1.00 & 0.99 \\
Single female & 0.30 & 0.29 \\
Divorced female & & 0.37
\end{tabular}

TABLE 9

EFFECTS OF CHILDHOOD HISTORY ON FEMALE INCOME, MODEL

\begin{tabular}{lcccc}
\hline & \multicolumn{4}{c}{ Childhood History } \\
\cline { 2 - 5 } & $m \rightarrow m$ & $m \rightarrow s$ & $s \rightarrow m$ & $s \rightarrow s$ \\
\hline Expected wage & 1.00 & 0.79 & 0.75 & 0.54 \\
Expected family income & 1.00 & 0.87 & 0.85 & 0.68 \\
\hline
\end{tabular}

nurturing their children, a number close to what Olson (1983) reports. Single parents spend a larger fraction of their income on children, both in the model and in the data. Olson (1983) reports that for a single parent the cost of raising three children (again other than housing and food) is about 33\% of parent's income. In the model, single mothers spend about $35 \%$ of their income on children, and they have about three children on average.

The model also generates several other interesting features regarding investment in children and the intergenerational persistence of economic status. Children from single-female families tend to do much worse. This is because their mothers do not have much time or money to invest in them. A single mother has less time for work, nurture, and leisure because she has more children on average, i.e., more of her time is absorbed on the fixed costs of child rearing. Since she earns less money than a married couple, she has less resources to invest in her offspring also. Additionally, single mothers tend to have more children than do married ones. The result of these facts is a lower level of human capital investment per child in a single female family; see Table 8 .

Table 9 shows the effect of family background on a female's income. A girl growing up in a household with a single mother $(s \rightarrow s)$ can expect to enjoy only two-thirds of the family income of one growing up with both parents $(m \rightarrow m)$. She is much more likely ( $44 \%$ versus $20 \%$ ) to experience an out-of-wedlock birth $(s \rightarrow m$ or $s \rightarrow s)$ or a divorce $(m \rightarrow s)$ than the girl from a two-parent home too; see Table 10.

\subsection{Nash Bargaining}

"Marry above thy match, and thou'lt get a master." Benjamin Franklin (1740)

How does Nash bargaining work in the model? The Nash bargaining solution solves a Pareto problem between husband and wife, a fact that is easy to show. Therefore, there exists some set of weights $\lambda$ and $(1-\lambda)$ such that solving a 
TABLE 10

EFFECTS OF CHILDHOOD HISTORY ON FEMALE MARITAL EXPERIENCE, MODEL

\begin{tabular}{lcccc}
\hline & \multicolumn{4}{c}{ Adult History } \\
\cline { 2 - 5 } Childhood History & $m \rightarrow m$ & $m \rightarrow s$ & $s \rightarrow m$ & $s \rightarrow s$ \\
\hline$m \rightarrow m$ & 0.80 & 0.09 & 0.08 & 0.03 \\
$m \rightarrow s$ & 0.73 & 0.11 & 0.11 & 0.06 \\
$s \rightarrow m$ & 0.71 & 0.11 & 0.11 & 0.06 \\
$s \rightarrow s$ & 0.56 & 0.17 & 0.16 & 0.12 \\
\hline
\end{tabular}

type- $\left(x_{i}, z_{j}, \gamma_{h}\right)$ young couple's Nash bargaining problem, $\mathrm{P}(7)$, is equivalent to solving the Pareto problem

$$
\begin{aligned}
& \max _{l, n, t, d, k}\{(1-\lambda)\{F(c, e, k, 1-l-t) \\
& +\beta \sum_{v=1}^{S} \sum_{l=1}^{S} \sum_{n=1}^{m}\left[W_{2}\left(x_{v}, z_{l}, \gamma_{n}, k\right) I_{2}^{m}\left(x_{v}, z_{l}, \gamma_{n}, k\right)\right. \\
& \left.\left.+G_{2}\left(x_{v}, k, z_{l}\right)\left[1-I_{2}^{m}\left(x_{v}, z_{l}, \gamma_{n}, k\right)\right]\right] \Delta\left(\gamma_{n} \mid \gamma_{h}\right) X\left(x_{v} \mid x_{i}\right) Z\left(z_{l} \mid z_{j}\right)\right\} \\
& +\lambda\left\{M(c, e, k, 1-n)+\beta \sum_{v=1}^{S} \sum_{l=1}^{S} \sum_{n=1}^{m}\left[H_{2}\left(x_{v}, z_{l}, \gamma_{n}, k\right) I_{2}^{m}\left(x_{v}, z_{l}, \gamma_{n}, k\right)\right.\right. \\
& \left.\left.\left.+B_{2}\left(z_{l}, k\right)\left[1-I_{2}^{m}\left(x_{v}, z_{l}, \gamma_{n}, k\right)\right]\right] \Delta\left(\gamma_{n} \mid \gamma_{h}\right) X\left(x_{v} \mid x_{i}\right) Z\left(z_{l} \mid z_{j}\right)\right\}\right\}
\end{aligned}
$$

subject to (1) and (2). ${ }^{22}$ The Pareto weight $\lambda$ reflects the husband's bargaining power and is endogenously determined as a function of the state $\left(x_{i}, z_{j}, \gamma_{h}\right)$.

Figure 4 shows how this weight behaves as a function of the state $(x, z, \gamma)$. In this diagram the male's weight is set to zero for any marriage that is not viable. Now, take the case where the match quality variable has the high value. Observe that the male's bargaining strength increases with the level of his productivity, $z$, and decreases with his wife's, $x$. The same is true when the match quality variable takes on the low value. As can be seen, most matches end with a marriage. When match quality is low, nobody want to be stuck with a low type. Thus, the degree of assortative mating is fairly low. This may be an artifact of two-period nature of the model. If you reject your mate today, then you only have one more chance in the future. Hence, this may be rectified by adding more periods. Alternatively, this could be fixed up by having an individual's draw on the marriage market being influenced by his or her type. ${ }^{23}$

\footnotetext{
22 This does not say that the model's general equilibrium is Pareto optimal. In general, it is not.

${ }^{23}$ Fernandez and Rogerson (2001) study the relationship between marital sorting and inequality. In their work, agents are exogenously married according to some probability structure that depends on their type.
} 

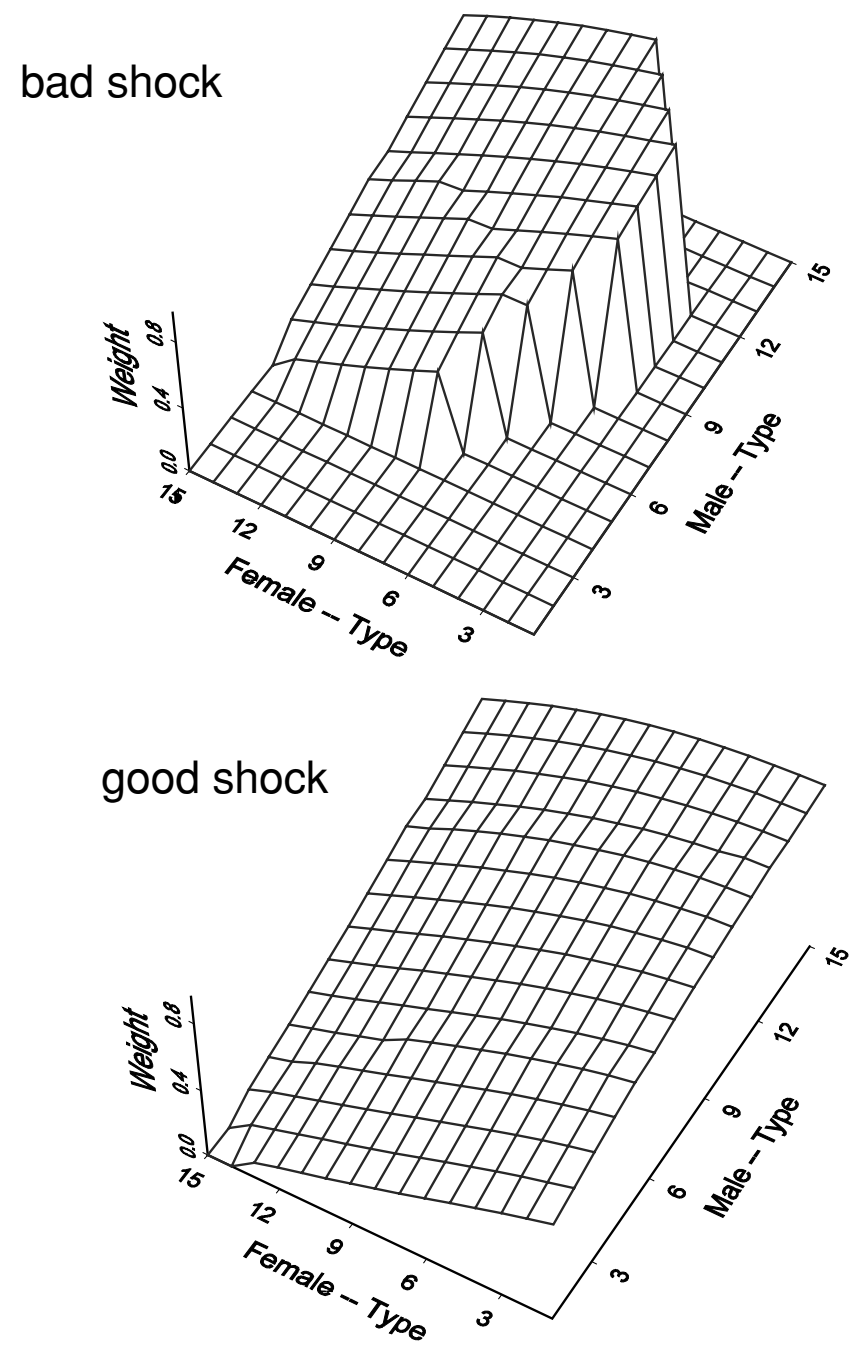

Figure 4

SET OF VIABLE MARRIAGES AND THE WEIGHT ON THE MALE'S UTILITY, NASH BARGAINING

Now, suppose that the model is solved holding the weight $\lambda$ fixed across states. For example let $\lambda=0.5$, which gives husband and wife an equal say in family decision making, so to speak. The number of marriages plummets in equilibrium from about 85 to $49 \%$. Why? When the weights are fixed, utility cannot be transferred from one party to the other in order to prevent a breakup and therefore not nearly as many marriages are sustainable. The degree of positive assortative mating is much higher than under the Nash bargaining solution. Figure 4 also shows the set of unsustainable marriages in the economy with Nash bargaining, i.e., the set 

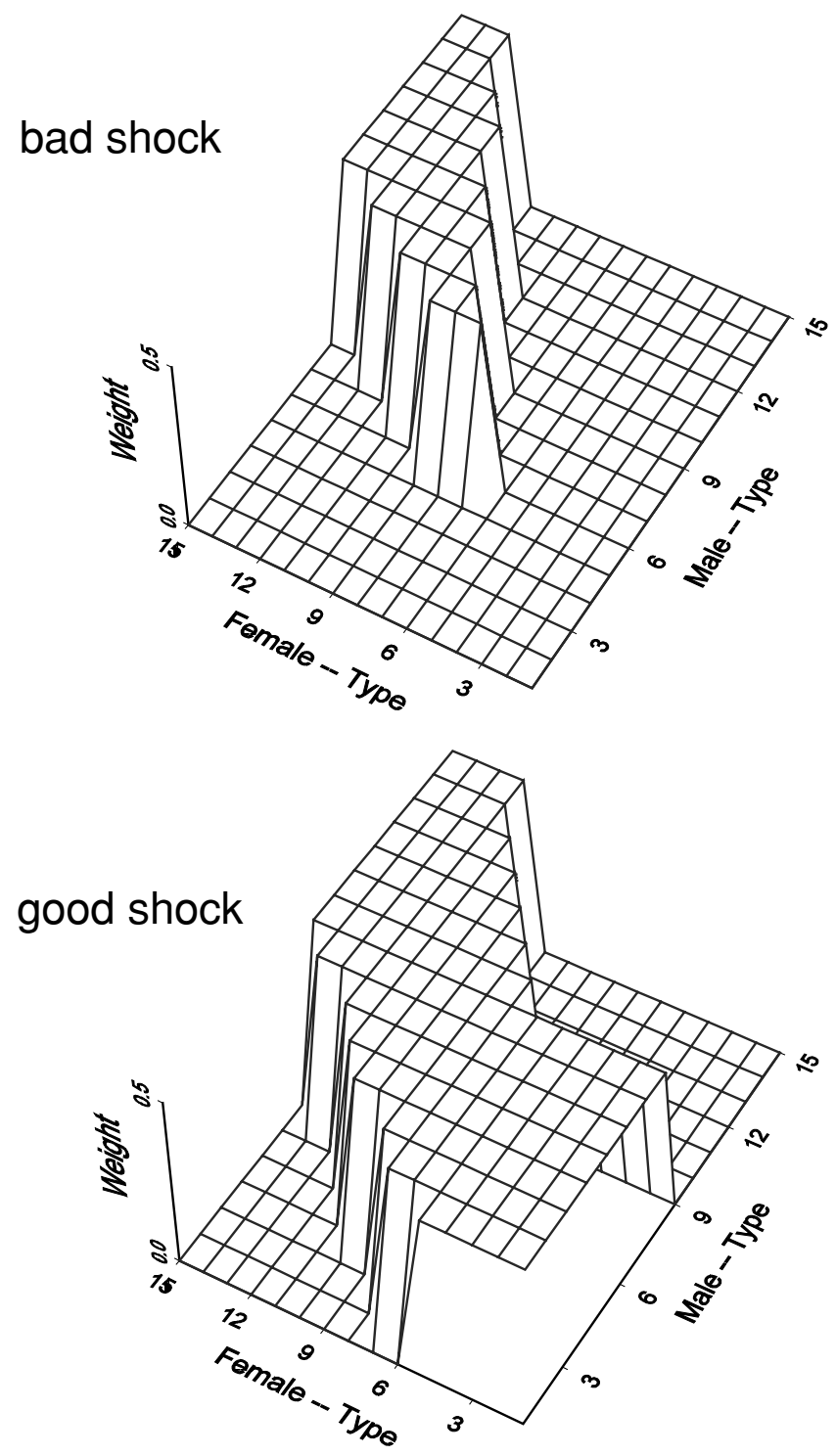

Figure 5

SET OF VIABLE MARRIAGES AND THE WEIGHT ON THE MALE'S UTILITY, FIXED WEIGHT PROBLEM

of $(x, z, \gamma)$ for which $I_{1}^{s}(x, z, \gamma)=0$. (Recall that the male's weight is set to zero for any marriage that is not viable.) With a good match quality shock virtually all matches are sustainable. Even when the quality of the match is low most matches are sustainable. No female, however, wants a male from the low end of the distribution. Males are not quite as choosy. When each party's bargaining power is held fixed, there is a high degree of assortative mating as Figure 5 illustrates. Now, when the quality of the match is poor most marriages are not sustainable. 


\section{TWO PUBLIC POLICY EXPERIMENTS}

Child tax credits are designed to elevate the welfare of all children in the economy. They transfer income away from families without children to families with them. Child support payments are targeted at those children who experience a family breakup because their parents get divorced. Here, to ease the devastating impact that a divorce can have on family income, governments require fathers to pay child support to their former wives. To illustrate how a model such as this can be used, consider the effects of these two public policies. Before proceeding a caveat is in order: As was mentioned earlier, the model is still very primitive in nature so that the policy numbers that are generated must be taken with due caution.

6.1. Child Tax Credits. Suppose that all families with children, both single and two-parent families, are eligible to collect a child subsidy. This subsidy provides a tax credit per child equal to $0.5 \%$ of the average level of income in the benchmark economy. It is financed by a lump-sum tax equal to $1.0 \%$ of average income in the benchmark economy. What are the effects of this policy?

On the upside, the beneficial effects of the policy are twofold. First, poor families will get extra income that should allow them to invest more time and resources in their children. Second, it should make marriage a more attractive option for males, since single males are taxed without receiving any subsidy. On the downside, the attractiveness of marriage for females, however, might decline. Second, the beneficial aspects of this policy for children may be dissipated by larger family size.

The long-run health of the economy is not helped by this policy. First, the percentage of single mothers increases by about 5 percentage points. The percentage of children living with a young single mother rises by about 7 percentage points. This transpires because young single mothers tend to have more children than married ones, and because the policy promotes fertility. The (annualized) population growth rate rises from 0.13 to $1.07 \%$. Single mothers now have 3.9 children as compared with 3.3 for the benchmark economy. Married women now average 2.1 children (versus 1.8 previously).

These effects are quite sizable. To understand why, it pays to artificially decompose the experiment into short- and long-run effects. For the short-run effects consider the impact of the child tax credit holding fixed the type distributions for young agents, or $\Phi_{1}$ and $\Omega_{1}$. This shuts down the effects on the economy from any induced changes in parental human capital investments. The percentage of single mothers rises by 2 percentage points. Both single and married women have more children (3.8 and 2.0). Married couples also substitute quality for quantity of children. The rise in female headship also reduces the average level of human capital investment in children. These effects operate to reduce the long-run quality of the mating pool, leading to a further 3 point rise in the percentage of single mothers. Note that it may take hundreds of years to reach the new steady state.

Average income in the economy falls by about $11 \%$. This occurs because there is now much less human capital investment in children. First, the increase in female 

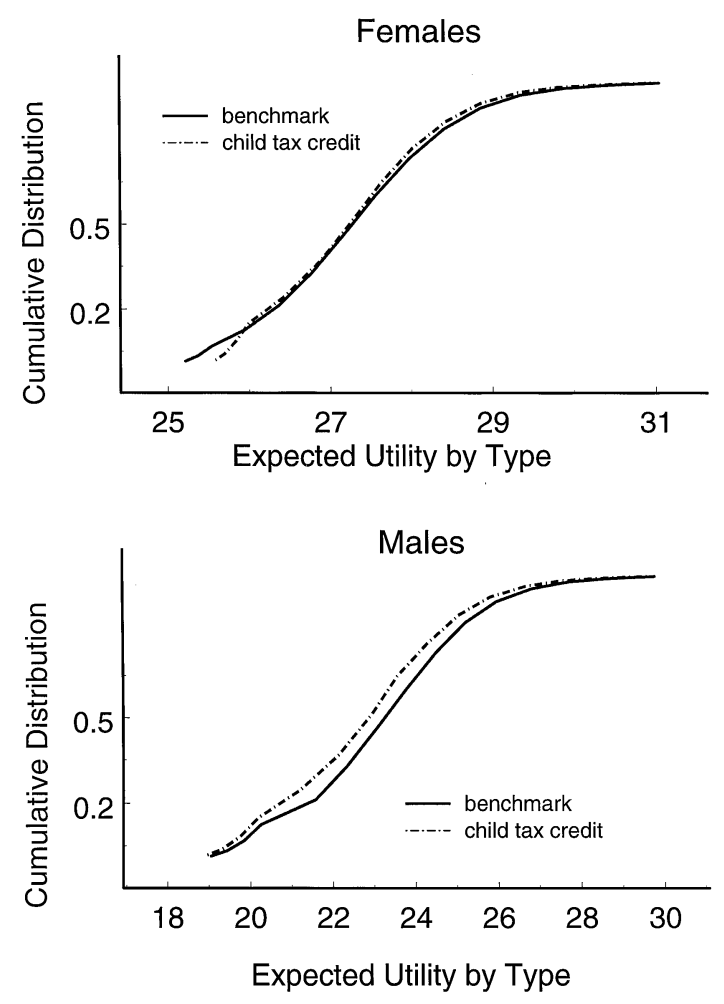

Figure 6

THE DISTRIBUTION OF EXPECTED UTILITY BY TYPE

headship is associated with a reduction in investment in children. Single mothers have less wherewithal-in terms of goods - than married couples. Second, with an increase in the quantity of children there is a fall in their quality. As the price of having an extra child drops, parents-married or otherwise-substitute quality for quantity. Figure 6 shows the impact of a child tax credit on the steady-state utility distributions for males and females. The policy makes males worse off in the sense that the utility distribution for the benchmark economy stochastically dominates the one for the economy with the child tax credit. This is not the case for females. Women in the lower strata of the economy are better off with a child tax credit. The rest are slightly worse off. The poorest women have the largest number of children so a tax credit helps them the most. Since women value children more than men (single men do not value them at all), the overall effect of the tax credit on women's expected utility is less detrimental than it is for men.

Endogenous fertility: Is it important to include a fertility decision in models of marriage and divorce? The answer is yes. To see this, redo the above experiment holding fixed the distribution of fertility across young woman. The effects of the child tax credit on a woman's fertility are therefore shut down. The presence of a 
child tax credit now has little impact on family structure. The percentage of single mothers living in the economy now rises slightly, an increase of only 0.3 percentage points (compared with 4.5 earlier). The percentage of children living a young single mother moves up by 0.5 percentage points (versus 7.0 before). Average income in the economy now rises by $2.1 \%$ (as opposed to $-11.4 \%$ previously)! When fertility is held fixed, families invest more in each of their children. This has an uplifting effect on society. The welfare gains from a child tax credit may be completely wiped out (and even reversed), therefore, by an increase in family size (especially for young single mothers).

6.2. Child Support Payments. The per-child rate of support is set in the benchmark equilibrium at $5.0 \%$ of the male's income. What is the effect of this policy? The answer is obtained by comparing the benchmark equilibrium to one without child support.

The removal of child support leads to a 0.65 point drop in the percentage of marriages. This is caused by both a rise in the number of young single females ( 0.8 percentage points) and an increase in divorces among the old ( 0.3 percentage points). Average income falls by about $1 \%$. The rate of growth in the population rises ever so slightly from 0.13 to $0.19 \%$. These effects seem moderate. The question is why.

One would expect that child support would make marriage and divorce less attractive for males and more attractive for females. The net impact will depend on which party is more likely to walk from a marriage. When child support is eliminated, marriages between high-type males and low-type females turn out to be more likely to break up. Without child support, a high-type male demands more than his low-type wife is willing to bear. Marriages between low-type males and high-type females, however, are less likely to dissolve. With child support in place, high-type females ask for more than a low-type male is willing to contribute to a marriage. The net effect on the equilibrium number of divorces is very small. Some of the drop in the equilibrium number of marriages derives from the fact that divorced mothers now invest less in their children (about a $7 \%$ drop in $e$ ) and this drives down the long-run quality of the mating pool. This can be seen by examining the impact of removing child support, which is done by holding the type distributions for young agents, or $\Phi_{1}$ and $\Omega_{1}$, fixed. Again, this turns off the effects on the economy from any induced changes in parental human capital investments. When this is done the number of marriages drops by 0.45 percentage points. Hence, about 0.20 percentage points of the fall in the number of marriages is due to the drop in the long-run quality of the mating pool.

Nash bargaining, again: The elimination of child support leads to some interesting reallocations within the family. When child support is eliminated an older female has a lower threat point. So her husband has relatively more bargaining power. Let $\mathcal{B}_{2}$ and $\mathcal{N}_{2}$ denote the combinations of $(x, z, \gamma, k)$ that generate viable marriages among the old in the benchmark and no-child support equilibriums. The old male's weight increases for each and every $(x, z, \gamma, k) \in \mathcal{B}_{2} \cap \mathcal{N}_{2}$. The average 


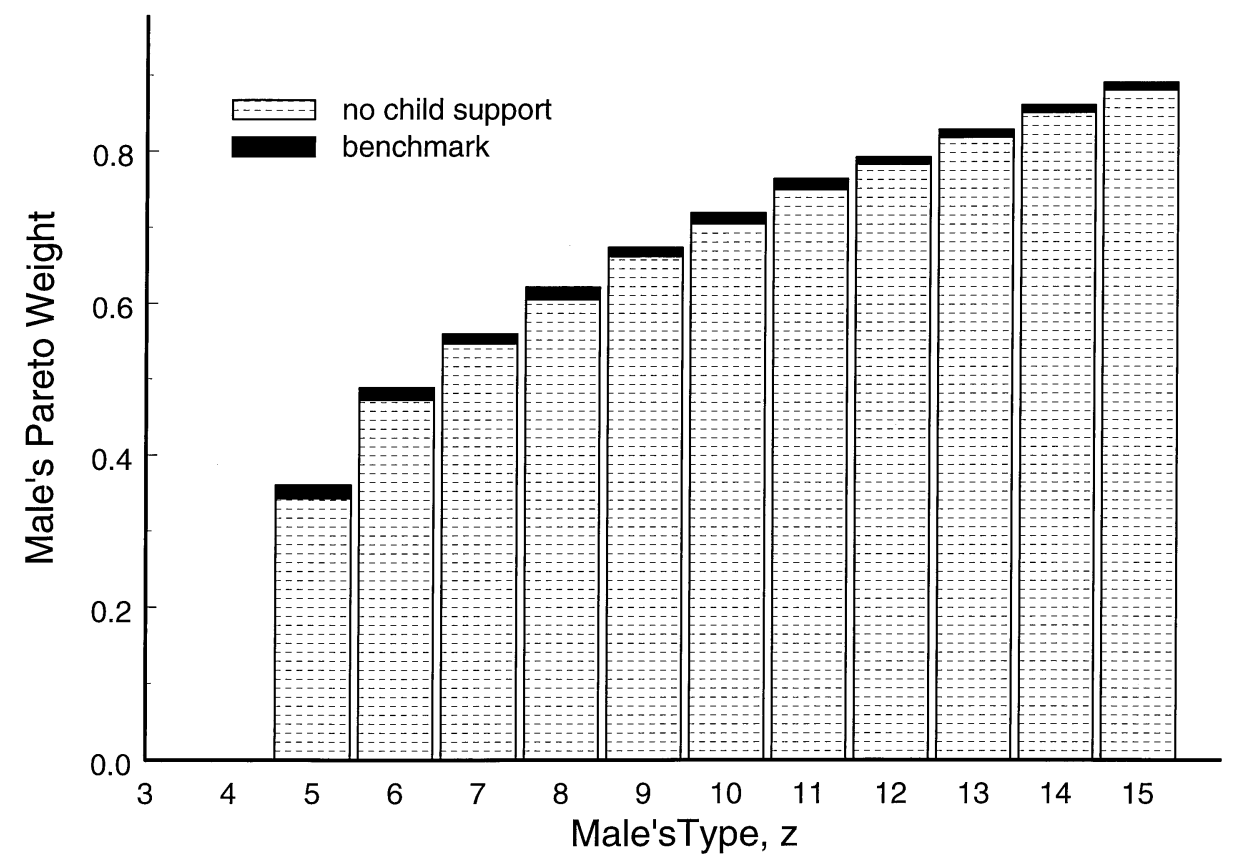

FIGURE 7

CHANGE IN BARGAINING POWER, YOUNG MALES

weight for males rises from 0.57 to 0.60 . Older females do indeed work more. ${ }^{24}$ Their leisure falls by almost 4 percentage points. Almost all of this is due to increased work in the market. (These changes are also due in part to the fact that high-type women constitute a larger fraction of marriages now.) Now, consider the impact on a young male's weight. Denote by $\mathcal{B}_{1}$ and $\mathcal{N}_{1}$ the combinations of $(x, z, \gamma)$ that generate viable marriages among the young in the benchmark and no-child support steady states. Surprisingly, a young male's weight decreases for each and every $(x, z, \gamma) \in \mathcal{B}_{1} \cap \mathcal{N}_{1}$ ! Why? A young female realizes that the gains from being married when she is old are lower when there is no child support in place. Hence, she will be more reluctant to marry when she is young. She demands more from her young suitor. Figure 7 shows the decline in the young male's weight, $\lambda$, that occurs when child support is withdrawn-the figure shows the average weight for each type of married male. On average, the young male's weight falls from 0.61 to 0.60 . Therefore, some of the gains that males realize when child support is removed are redistributed back to females. A young married female's leisure rises by 1.8 percentage points, on average.

\footnotetext{
${ }^{24}$ To calculate the average one needs to know how many type- $(x, z, \gamma, k)$ marriages there are. The distribution of marriages will be different for the benchmark and no-child support economies. The average was computed using the distribution from the benchmark economy, so as to not contaminate the changes in the male's weights with the shift in the distribution.
} 
Last, the manner in which households undertake their decision making appears to be important for analyzing the consequences of economic policy. To see this, suppose that the Nash bargaining weights are held at their benchmark values when child support payments are eliminated. Now, the equilibrium number of marriages plummets by 10 percentage points. Average income drops by $18 \%$. A marriage is no longer as flexible as before. One party is less able to transfer utility to the other in order to keep the marriage viable. ${ }^{25}$

\section{CONCLUSION}

An overlapping generations model of marriage, divorce, and the quantity and quality of children is developed here to study the distribution of income. Singles meet in a marriage market and are free to accept or reject marriage proposals from the opposite sex. Likewise, married agents must decide whether or not to remain with their current spouses. Within a marriage, decisions about how much to work, the number of children, and the amount of time and money to invest per child are decided by Nash bargaining. In the model's general equilibrium, some adults are married while others are not. Some females have children in wedlock, others out of it. Marital status and income are related. Families headed by a single mother are the poorest. Likewise, fertility and income are also related. Fertility declines with income. Single mothers have the most children. Children raised by a single mother have a greater tendency (relative to other children) to grow up poor due to a lack of human capital investment. The distribution of income is more skewed when family size is taken into account.

Can social policies be designed to improve society's welfare? Future generations of the prototype model may shed insight on such questions. To illustrate how the model can be used in such a context the impact of child tax credits and child support payments are considered. When the number of children is held fixed, child tax credits increase the amount of income per child. But, the number of children cannot be held fixed since the policy promotes an increase in family size. It also reduces the attractiveness of marriage for females. On net, child tax credits fail to elevate the well-being of society.

Child support payments are aimed at insulating children from the drop in family income that occurs when their parents divorce. Child support payments should make divorce more attractive for females and less attractive for males. The effect on the equilibrium number of marriages is small. This is because child support payments reduce marital breakups between high-type males and low-type females, but promote breakups between low-type males and high-type females. This experiment highlights the fact that the form of household decision making may be important for designing public policy. Child support payments transfer resources away from husbands toward wives, other things equal. This strengthens the hands

\footnotetext{
${ }^{25}$ An efficient marriage contract would specify, at the time of marriage, child support and alimony payments as a function of each party's type. Such contracts will not be time consistent, so enforceability is an issue. Modeling such contracts would greatly complicate the current analysis. Flinn (2000) analyzes the determination of child support payments between divorced parents.
} 
of wives vis à vis their husbands. With Nash bargaining, utility can be transferred away from a husband to a wife to keep a marriage sustainable, so long as it is in the husband's interest to do so. But, to the extent that single males have the option to remain unmarried, part of this transfer will be undone by renegotiating the terms of marriage. Last, the model is still too crude to place confidence in the results for these two policy experiments. Future generations of the model, however, may be able to enlist in public service.

\section{REFERENCES}

Aiyagari, S. R., J. Greenwood, and N. Guner, "On the State of the Union," Journal of Political Economy 108 (April 2000), 213-44.

Andolfatto, D., AND P. A. Gomme, "Unemployment Insurance and Labor-Market Activity in Canada," Carnegie-Rochester Conference Series on Public Policy 44 (1996), 4782.

Attanasio, O., And V. Lechene, "Tests of Income Pooling in Household Decisions," Review of Economic Dynamics 5 (2002), 720-48.

Becker, G. S., AND R. J., Barro, "A Reformulation of the Economic Theory of Fertility," Quarterly Journal of Economics 103 (February 1988), 1-25.

, AND N. Tomes, "Human Capital and the Rise and Fall of Families," Journal of Labor Economics 4 (supp. 1986), S1-S39.

BRowning, M., "Children and Household Economic Behavior," Journal of Economic Literature 30 (September 1992), 1434-75.

Chiaptori, P., B. Fortin, and G. Lacroix, "Marriage Market, Divorce Legislation, and Household Labor Supply," Journal of Political Economy, 110 (2002), 37-72.

CORNwell, C., AND P. RuPERT, "Unobservable Individual Effects, Marriage and the Earnings of Young Men," Economic Inquiry 35 (April 1997), 285-94.

Cutler, D. M., AND L. F. Katz, "Rising Inequality? Changes in the Distribution of Income and Consumption in the 1980s," American Economic Review 82 (1992), 546-51.

Fernandez, R., AND R. Rogerson, "Sorting and Long-Run Inequality," Quarterly Journal of Economics 116 (November 2001), 1305-41.

Flinn, C., "Modes of Interaction between Divorced Parents," International Economic Review 41 (August 2000), 545-78.

Garfinkel, I., AND D. Oellerich, "Noncustodial Fathers' Ability to Pay Child Support," Demography 26 (May 1989), 219-33.

Grall, T., "Child Support for Custodial Mothers and Fathers," Current Population Reports, P60-212 (Washington: U.S. Bureau of the Census, October 2000).

Greenwood, J., N. Guner, and J. A. Knowles, "Women on Welfare: A Macroeconomic Analysis," American Economic Review 90 (May 2000), 383-88.

Hansen, G. D., AND A. Imrohoroglu, "The Role of Unemployment Insurance in an Economy with Liquidity Constraints and Moral Hazard," Journal of Political Economy 100 (February 1992), 118-42.

Knowles, J. A., "Parental Decisions and Equilibrium Inequality," Ph.D. Dissertation, University of Rochester, 1999.

Kydland, F. E., and E. C. Prescott, "Time to Build and Aggregate Fluctuations," Econometrica 50 (November 1982), 1345-70.

Loury, G. C., "Intergenerational Transfers and the Distribution of Earnings," Econometrica 49 (July 1981), 843-67.

Lundberg, S., R. A. Pollak, and T. J. Wales, "Do Husband and Wives Pool Their Resources: Evidence from the United Kingdom Child Benefit," Journal of Human Resources 32 (Summer 1997), 463-80.

Manser, M., AND M. Brown, "Marriage and Household Decision-Making: A Bargaining Analysis," International Economic Review 21 (February 1980), 31-44. 
McElroy, M. B., And M. J. Horney, "Nash-Bargained Household Decisions: Toward a Generalization of the Theory of Demand," International Economic Review 22 (June 1981), 333-49.

McGratten, E. R., And R. Rogerson, "Changes in Hours Worked since 1950," Federal Reserve of Minneapolis Quarterly Review 22 (Winter 1998), 2-19.

McLanahan, S., And G. SAnDefur, Growing up with a Single Parent: What Hurts and What Helps (Cambridge and London: Harvard University Press, 1994).

Mortensen, D. T., "Matching: Finding a Partner for Life or Otherwise," American Journal of Sociology 94 (supp. 1988), 215-40.

Olson, L., Costs of Children (Massachusetts: Lexington Books, 1983).

Pareto, V., Cours d'Economie Politique (Paris: Pichon Libraire, 1896).

Razin, A., And U. Ben-Zion, "An Intergenerational Model of Population Growth," American Economic Review 65 (December 1975), 923-33.

Regalia, F., AND J. V. Ríos-Rull, "What Accounts for the Increase in Single Households?" Mimeo, Universitat Pompeu Fabra, 2001.

Robinson, W. C., "The Time Cost of Children and Other Household Production," Population Studies 41 (July 1987), 313-23.

Rubalcava, L., ANd D. Thomas, "Family Bargaining and Welfare," Mimeo, UCLA, 2000.

Schoeni, R. F., "Marital Status and Earnings in Developed Countries," Journal of Population Economics 8 (November 1995), 351-59.

Stokey, N. L., "Shirtsleeves to Shirtsleeves: The Economics of Social Mobility," in D. P. Jacobs, E. Kalai, and M. I. Kamien, eds., Frontiers of Research in Economic Theory: The Nancy L. Schwartz Lectures 1983-1997 (Cambridge: Cambridge University Press, 1998), 210-41.

Tauchen, G., "Finite State Markov-Chain Approximation to Univariate and Vector Autoregressions," Economics Letters 20 (1986), 177-81.

U.S. Bureau of THE Census, Statistical Abstract of United States, 2000.

Ventura, S. J., AND C. A. BACHrach, "Nonmarital Childbearing in the United States, 19401999," National Vital Statistics Report 48 (Hyattsville, MD: National Center for Health Statistics, October 2000).

Weiss, Y., "The Formation and Dissolution of Families: Why Marry? Who Marries Whom? and What Happens upon Divorce?" in M. R. Rosenzweig and O. Stark, eds., Handbook of Population and Family Economics (Amsterdam: Elsevier Science, 1997), 81-123. 